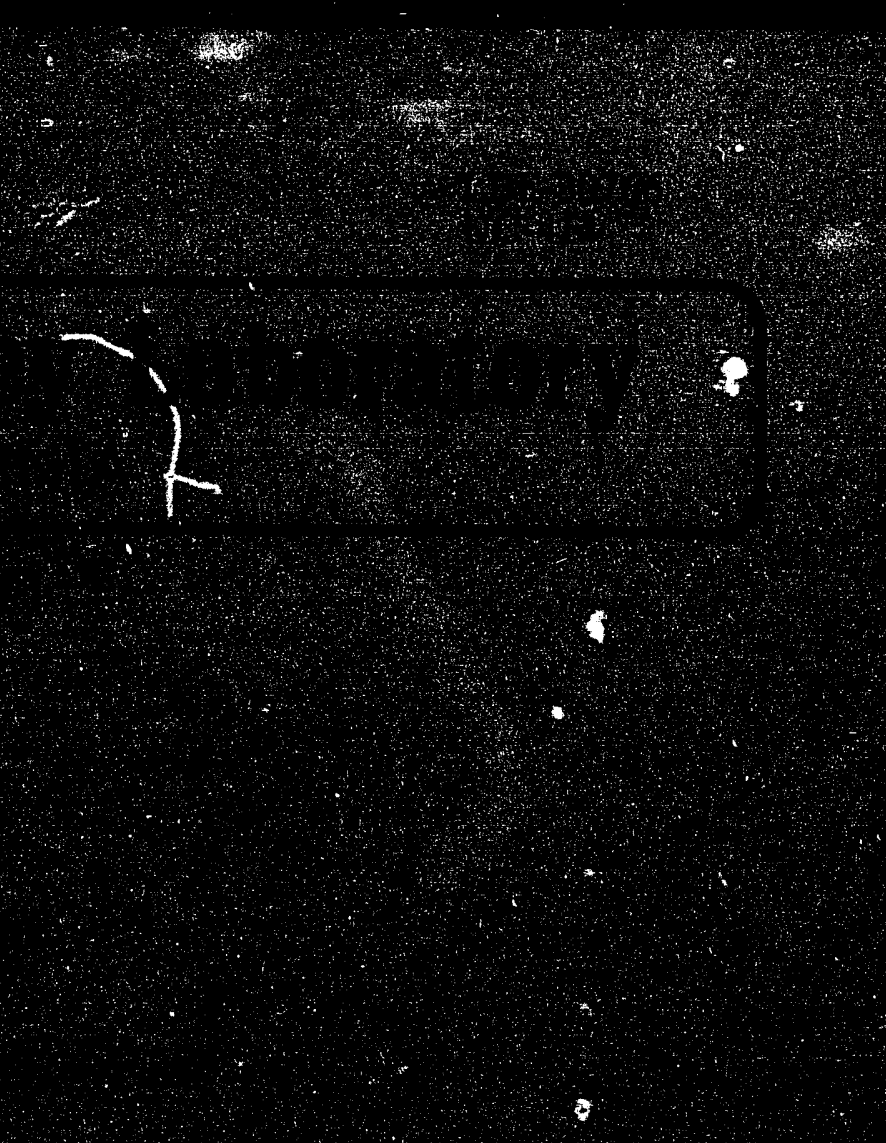

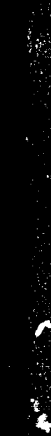




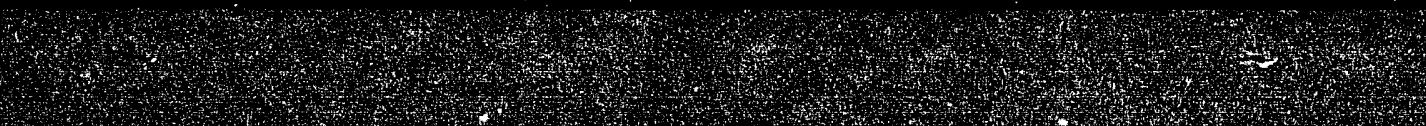

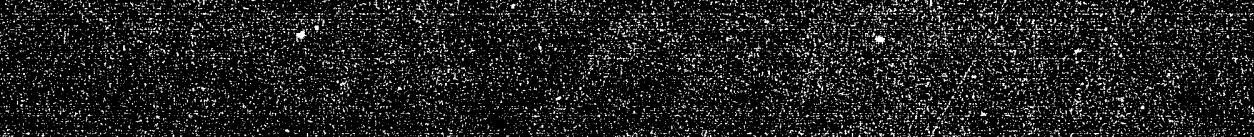
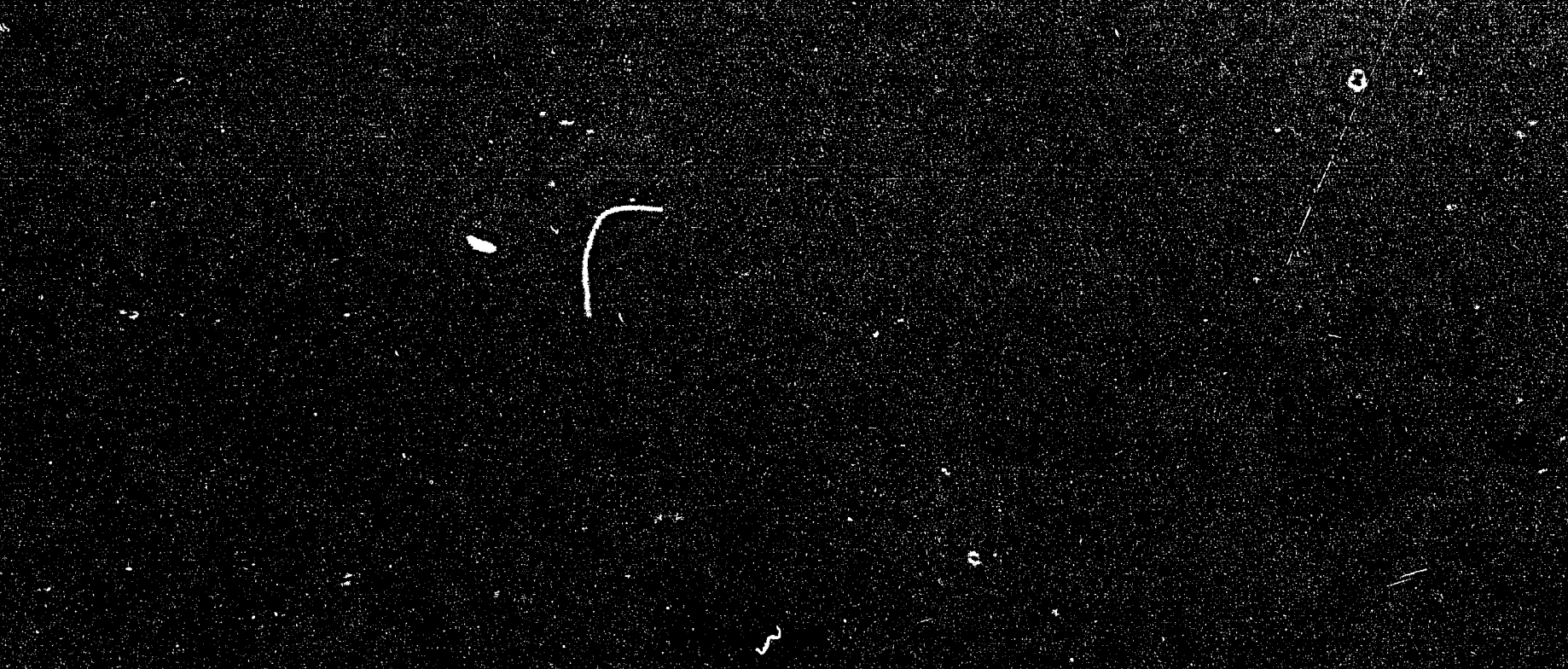

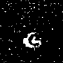

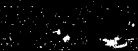

of

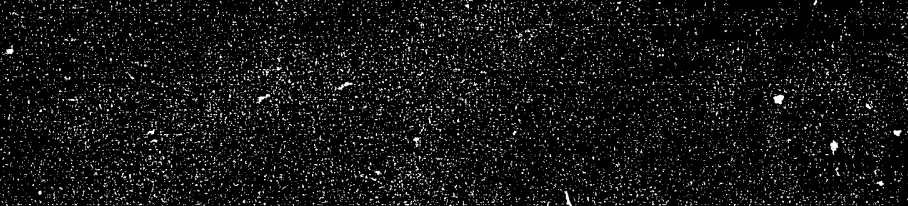

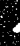
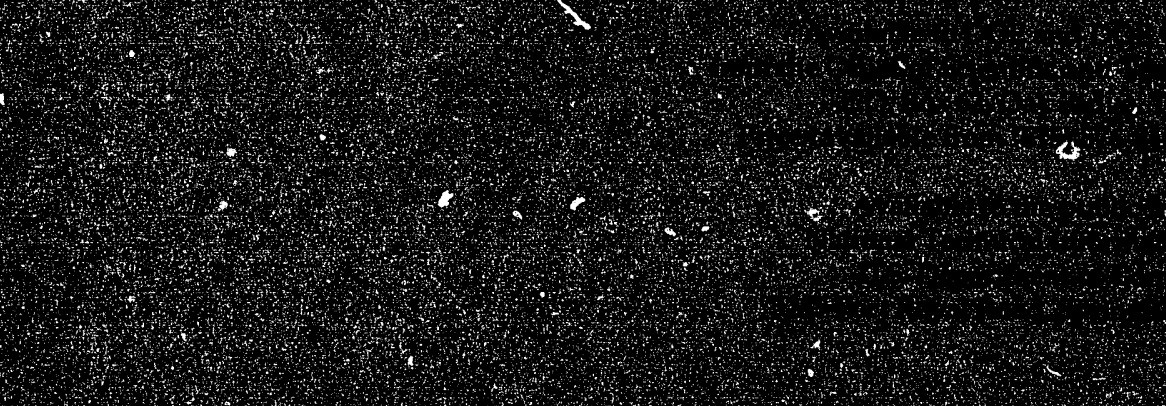
LBL --30766

DE92 000649

\title{
AN UPDATE ON PASSIVE CORRECTORS FOR THE SSC DIPOLE MAGNETS*
}

\author{
Michael A. Green \\ Lawrence Berkeley Laboratory \\ University of California \\ Berkeley, CA 94720
}

May, 1991

This report has been reproduced directly from the best available copy.

*This work was supported by the Office of High Energy and Nuclear Physics, High Energy Physics Division, U.S. Dept. of Energy, under Contract No. DE-AC03-76SF00098. 


\section{TABLE OF CONTENTS}

Introduction

Conductor and Block Contribution to the Magnetization

Sextupole and Decapole

The Elimination of Magnetization Sextupole at Injection by Changing the Superconductor Filament Diameter in One or More Coil Blocks

The Elimination of Magnetization Sextupole and Decapole by Adding Passive Superconductor to the Inner Bore of the Dipole

The Effect of Filament Diameter and Midplane Angle on the Correction of Magnetization Sextupole and Decapole in the SSC Dipole Using Passive Superconductor Correctors in the Magnet Bore

Correction with Ferromagnetic Wires and Passive

Superconductor Inside the Magnet Bore

Compensation of Magnetization Sextupole and Decapole Decay due to Flux Creep

Concluding Comments

Acknowledgements 


\title{
AN UPDATE ON PASSIVE CORRECTORS FOR THE SSC DIPOLE MAGNETS
}

\author{
Michael A. Green \\ Lawrence Berkeley Laboratory \\ University of California \\ Berkeley, CA. 94720
}

May 1991

\section{INTRODUCTION}

Unexplained sextupole and other higher multipoles were observed in superconducting dipole magnets as early as 1970 1,2. Experiments at that time revealed that the dipole magnets produced a dipole field which was very rich in sextupole, decapole and other symmetric multipoles at zero current after the magnet had been charged to a much high field. If the magnet had had no previous charging history, this field at zero current was absent. Similar behavior was also observed in quadrupole magnets at about the same time 3 . The tie between superconductor magnetization and this residual field was made very early 4,5 . The effects of the magnetization the superconductor was observed in the Brookhaven CBA magnets 6 and the Fermilab Tevatron soon after it started operation 7. Magnetization of the superconductor did not become a real problem until superconducting storage rings were developed. By 1983, it became clear that the symmetric multipole generated by the superconductor magnetization would become a potential problem for the SSC 8 . The magnetization sextupole issue pushed the development of fine filament superconductor for the SSC and it is one of several factors which contributed to the decision to raise the injection energy from $1 \mathrm{TeV}$ to 1.8 to $2.0 \mathrm{Tev} 9$. The effects of superconductor magnetization also had some effect on the decision to increase the aperture of the dipole coil from $\mathbf{4 0}$ millimeters to 50 millimeters.

The concept of correction of the magnetization sextupole became a topic of discussion as soon as it was realized that superconductor magnetization could have a serious effect on the SSC beam during injection. Several methods of correction were proposed. These included 1) correction with active bore tube windings like those on the HERA machine which correct out magnetization sextupole and the sextupole due to iron saturation 10,2 ) correction with persistent sextupole windings mounted on the bore tube 11,3 ) correction using passive superconductor 12,4 ) correction using ferromagnetic material ${ }^{13}$, and 5) correction using oriented magnetized materials $\mathbf{1 3}$. This report deals with the use of passive superconductor to correct the magnetization sextupole. Two basic methods are explored in this report: 1) One can correct the magnetization sextupole by changing the diameter of the superconductor filaments in one or more blocks of the SSC dipole. 2) One can correct the magnetization sextupole and decapole by mounting passive superconducting wires on the inside of the SSC dipole coil bore. In addition, an assessment of the contribution of each conductor in the dipole to the magnetization sextupole and decapole is shown. 


\section{CONDUCTOR AND BLOCK CONTRIBUTION TO THE MAGNETIZATION SEXTUPOLE AND DECAPOLE}

Calculation of the magnetization multipoles in the SSC DX-201 magnet was done on a conductor by conductor and a block by block basis using the Lawrence Berkeley Laboratory SCMAG04 computer code 14,15. The method of calculation involved calculating the sextupole and decapole in one conductor while the other conductors were suppressed. The field which determines the orientation of the magnetization current doublets is determined by the flux line direction due to the field generated by the transport current in all of the conductors. As a result, the suppressed conductor had to be present in order to generate the transport current field but the strength of the current doublet had to be zero in order that the conductor not contribute to the magnetization multipole field. This technique was applied on a conductor by conductor basis in all of the 45 conductors which make up one quarter of the magnet. Standard dipole symmetry was applied to the conductor by conductor calculation. The block by block calculation was done in the same way as the conductor by conductor calculation.

Table 1 shows the ratios of sextupole and decapole to the dipole at a radius of 10 millimeters at an injection central induction of 0.33 tesla (the dipole term). The conductors which contribute positive and negative sextupole and decapole are shown in Figures 1 and 2. Table 2 presents the results of the block by block calculation at three different injection inductions; 0.15 tesla, 0.33 tesla, and 0.66 tesla. At the time this report was written, the injection induction for the Superconducting Super Colliders was 0.6 tesla (The assumed injection energy is $1.8 \mathrm{TeV}$.) The small differences in the block by block sextupole and decapole ratios shown in Tables 1 and 2 is due to round off errors in the magnetization calculations.

From Table 1 and Table 2, one can see that the magnetization sextupole generated by block 1 is positive. The largest positive contribution (over one unit) comes from the cable on the magnet midplane. As on increases the angle moving off of the midplane, the positive sextupole contribution becomes smaller. The decapole from block 1 is for the most part also positive (except for the turn in block 1 at the highest angle from the midplane). Block 2 contributes a large negative sextupole and a negative decapole. (The highest angle turn in block 2 contributes a small positive decapole.) Block 3 contributes a negative sextupole and a positive decapole. Block 4 contributes a positive sextupole and a positive decapole. The overall contribution of the inner coil layer is negative sextupole and positive decapole. This is true for all injection fields as long as the magnetic field is going up and the turn around field is at least 0.1 tesla lower than the injection field.

Block 5, contributes very little net sextupole or decapole to the magnetization field despite the fact that it is the block where the field is the lowest and where the conductor critical current density is the highest. When one increases the injection field from 0.15 tesla to 0.66 tesla, the sextupole contribution of block 5 changes from positive to negative. The effects of superconductor penetration are most pronounced in this block. All of the conductors in block 6 produce negative magnetization sextupole at injection. Therefore, block 6 contributes a large negative magnetization sextupole to the injection field. The net magnetization decapole from the conductors in block 6 is negative but small. The outer layer generates a negative magnetization sextupole at injection which is larger than that generated by the inner layer. The magnetization decapole generated by the outer layer is smal! and negative. 

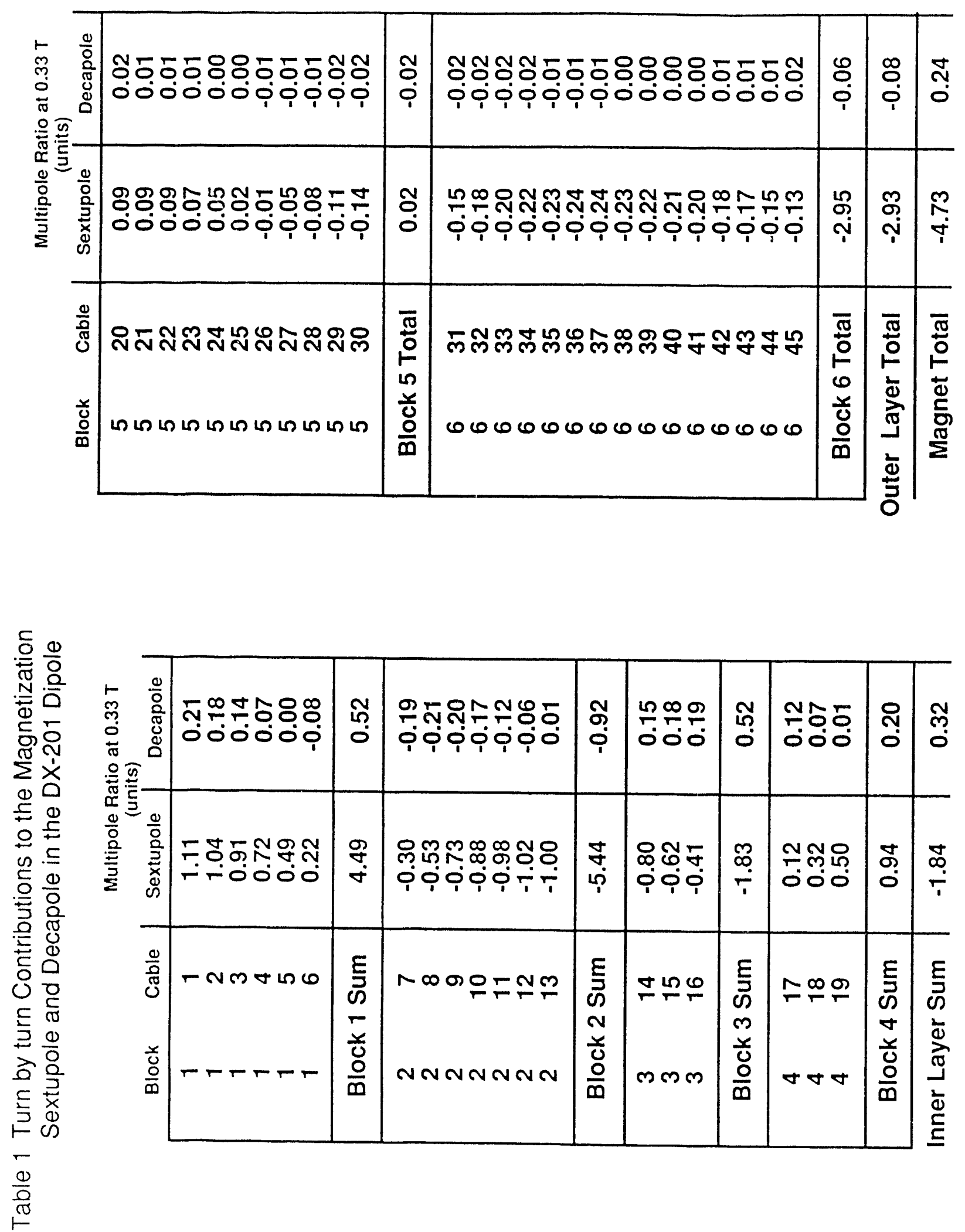
Figure 1

A QUARTER SECTION OF THE DX-201

SSC FIVE CENTIMETER BORE DIPOLE MAGNET SHOWING WHICH CONDUCTORS CONTRIBUTE

POSITIVE AND NEGATIVE MAGNETIZATION

SEXTUPOLE TO THE FIELD AT INJECTION

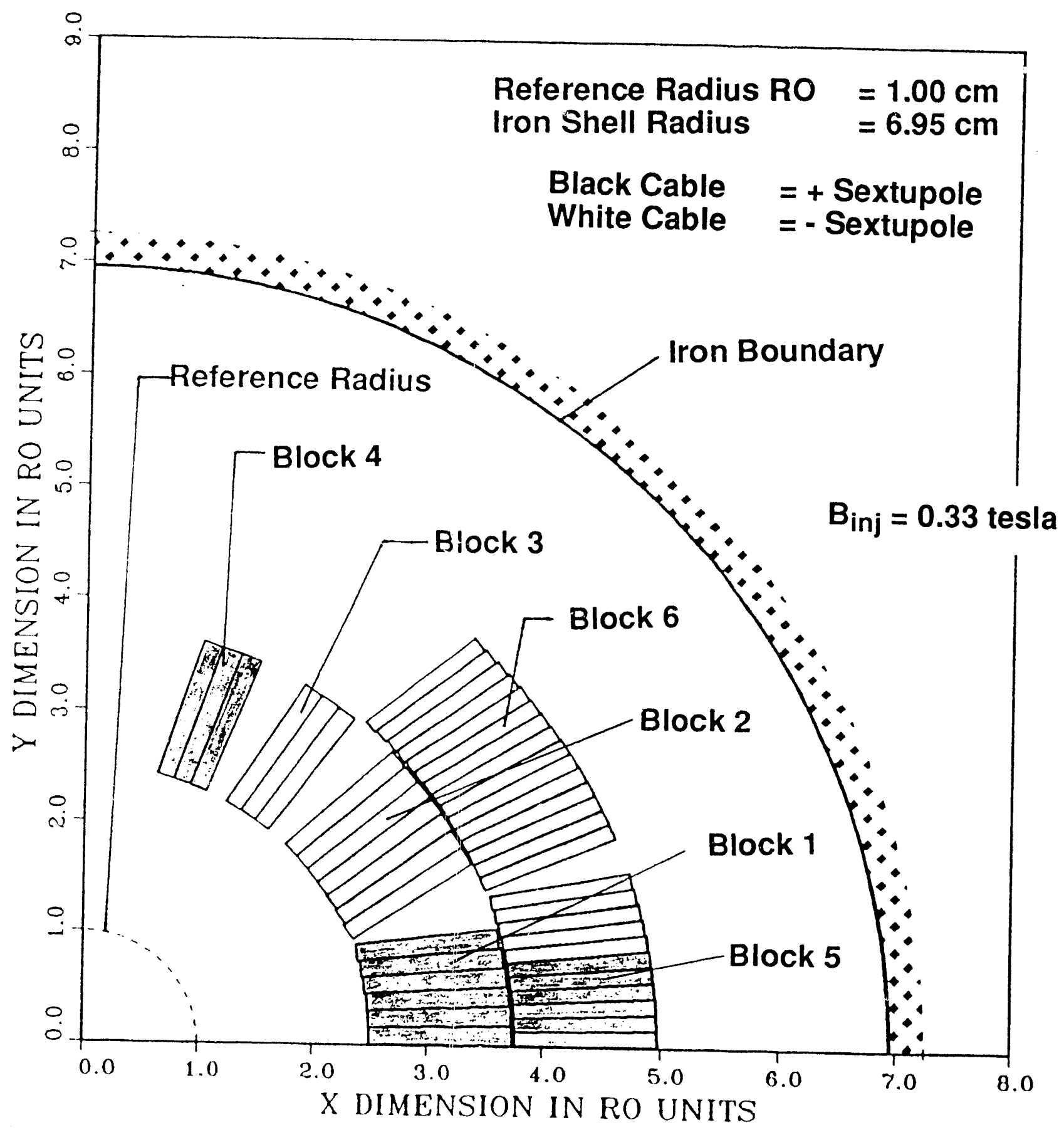


Figure 2

A QUARTER SECTION OF THE DX-201

SSC FIVE CENTIMETER BORE DIPOLE MAGNET SHOWING WHICH CONDUCTORS CONTRIBUTE

POSITIVE AND NEGATIVE MAGNETIZATION

DECAPOLE TO THE FIELD AT INJECTION

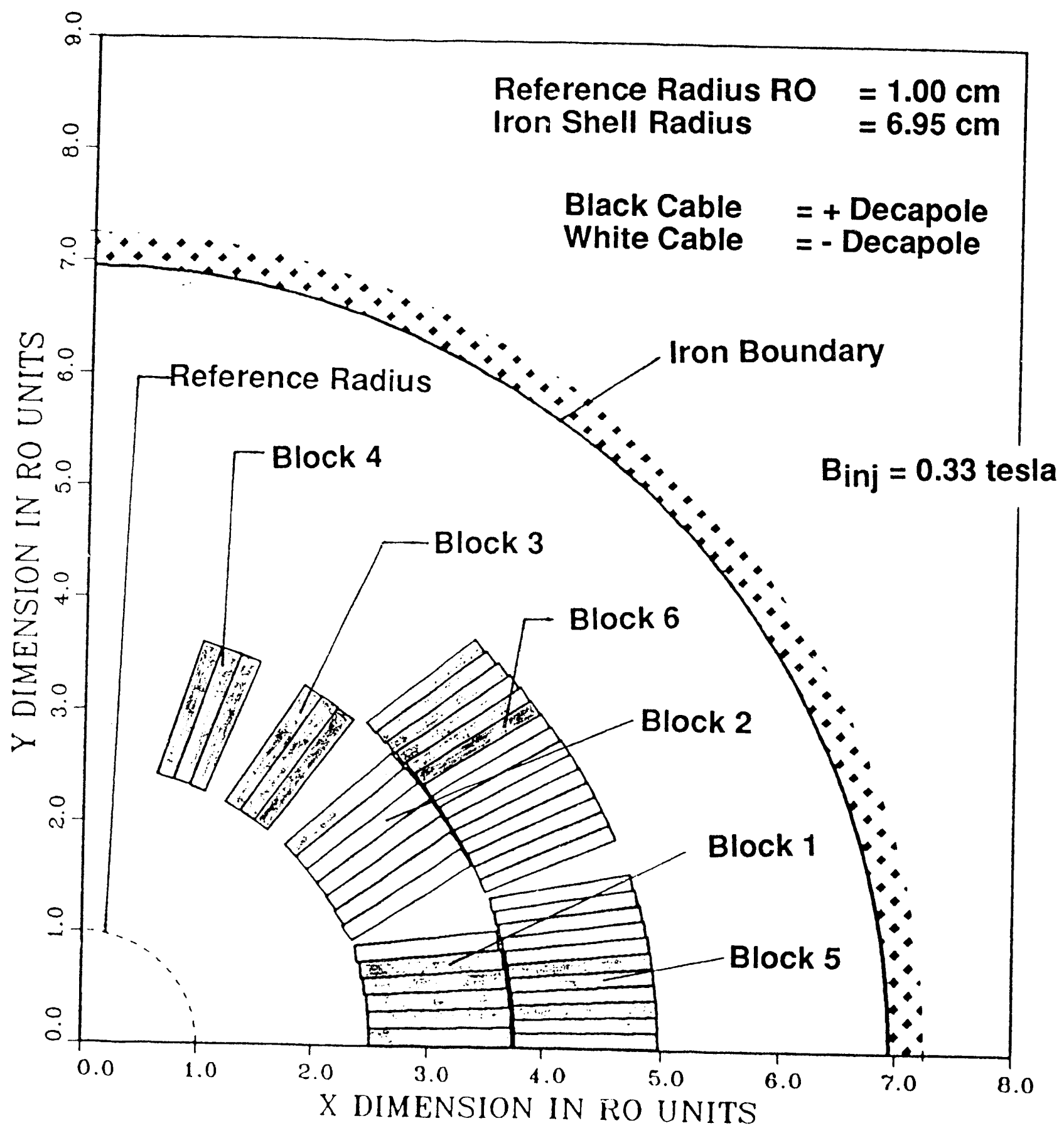


Table 2

BLOCK BY BLOCK CONTRIBUTIONS TO MAGNETIZATION SEXTUPOLE AND DECAPOLE IN A SSC DIPOLE AT VARIOUS CENTRAL INDUCTIONS

\begin{tabular}{|l|r|r|r|} 
& \multicolumn{3}{|c|}{ Sextupole Ratio (units) } \\
& Bo = 0.15 T & Bo = 0.33 T & Bo = 0.66 T \\
\hline Block 1 & 12.22 & 4.50 & 1.62 \\
Block 2 & -16.17 & -5.45 & -1.98 \\
Block 3 & -5.71 & -1.83 & -0.63 \\
Block 4 & 3.00 & 0.95 & 0.36 \\
Block 5 & 0.27 & 0.02 & -0.06 \\
Block 6 & -5.39 & -2.93 & -1.08 \\
\hline Entire Magnet & -11.78 & -4.74 & -1.77 \\
\hline
\end{tabular}

\begin{tabular}{|c|c|c|c|}
\hline & \multicolumn{3}{c|}{ Decapole Ratio (units) } \\
\hline & Bo = 0.15 T & Bo = 0.33 T & Bo = 0.66 T \\
\hline Block 1 & 1.42 & 0.51 & 0.19 \\
Block 2 & -2.74 & -0.93 & -0.34 \\
Block 3 & 1.70 & 0.55 & 0.20 \\
Block 4 & 0.68 & 0.21 & 0.08 \\
Block 5 & -0.01 & -0.03 & -0.02 \\
Block 6 & -0.02 & -0.06 & -0.03 \\
\hline Entire Magnet & 1.03 & 0.25 & 0.08 \\
\hline
\end{tabular}

Note: The disagreement between the $\mathrm{BO}=0.33 \mathrm{~T}$ conductor by conductor and the block by block calculations are due to small round off errors in the process of removing the magnetization terms which were unwanted when the calculations were made. 


\section{THE ELIMINATION OF MAGNETIZATION SEXTUPOLE AT INJECTION BY CHANGING THE SUPERCONDUCTOR FILAMENT DIAMETER IN ONE OR MORE COIL BLOCKS}

The uncorrected DX-201 SSC dipole coil shown in Figure 3 has a copper to superconductor ratio of 1.5 in the inner layer conductor. The outer layer conductor has a copper to superconductor ratio of 1.8. Both layers have superconductor filaments which are 6 microns in diameter. The metal packing factor for the conductor in the cables shown in Figure 3 is 0.76 for the inner cable and 0.74 for the outer cable. The assumed superconductor critical current density at $4.2 \mathrm{~K}$ and $5.0 \mathrm{~T}$ in conductor for both layers and all correctors is $2750 \mathrm{~A} \mathrm{~mm}^{-2}$. Figures 4 and 5 show the magnetization sextupole and decapole ratios as a function of central induction for the DX-201 dipole cross-section shown in Figure 3. The minimum cycle induction for the magnet cycle shown in Figure 4 is 0.05 tesla. The arrows on the magnetization curves show the direction of flux change. The points are used to identify the magnetization sextupole ratio $(N=3)$ and the magnetization decapole ratio $(N=5)$. The minimum cycle induction for the magnet cycle shown in Figure 5 is 0.25 tesla. It is useful to compare figures 4 and 5 with similar figures for DX-201 magnets with various types of passive superconductor correction.

B. C. Brown of Fermi Lab 16 suggested that having different filament diameters in different blocks could be used to reduce or eliminate the magnetization sextupole at injection. The easiest form of filament diameter variation is to have filaments of different diameters in the inner and outer layers of the magnet. Unfortunately, this approach does not work because both magnet layers contribute a negative sextupole to the overall magnetization sextupole.

In order to cancel the negative sextupole generated by the magnet, one must increase the diameter of the filaments in those conductors which produce a positive sextupole. (See Figure 1.) From Table 2 one can see that the simplest approach is to increase the diameter of the filaments in block 1 only. The procedure was tried using the SCMAG04 computer program. The filament diameter was increased so that the magnetization sextupole was made very near zeio over a wide range of injection inductions (with the central field rising) from 0.35 tesla on up. increasing the superconductor filament diameter in block 1 from 6 microns to 14 microns was enough to insure that the injection sextupole was made nearly zero over a wide range of injection inductions above 0.35 tesla. (See figure 6 with block 1 darkened to illustrate where the superconductor filament diameter was increased.) The larger sized filaments in block 1 acts as a passive corrector for the magnetization sextupole in the DX-201 SSC dipole. It should be noted that the increased filament diameter in block 1 reduces both the bulk current magnetization (which is proportional to the product of conductor critical currert density and filament diameter) and the intrinsic magnetization (which is proportional to the lower critical field and is independent of the filament diameter). 
Figure 3

A QUARTER SECTION OF THE DX-201

SSC FIVE CENTIMETER BORE DIPOLE MAGNET WITHOUT PASSIVE CORRECTORS

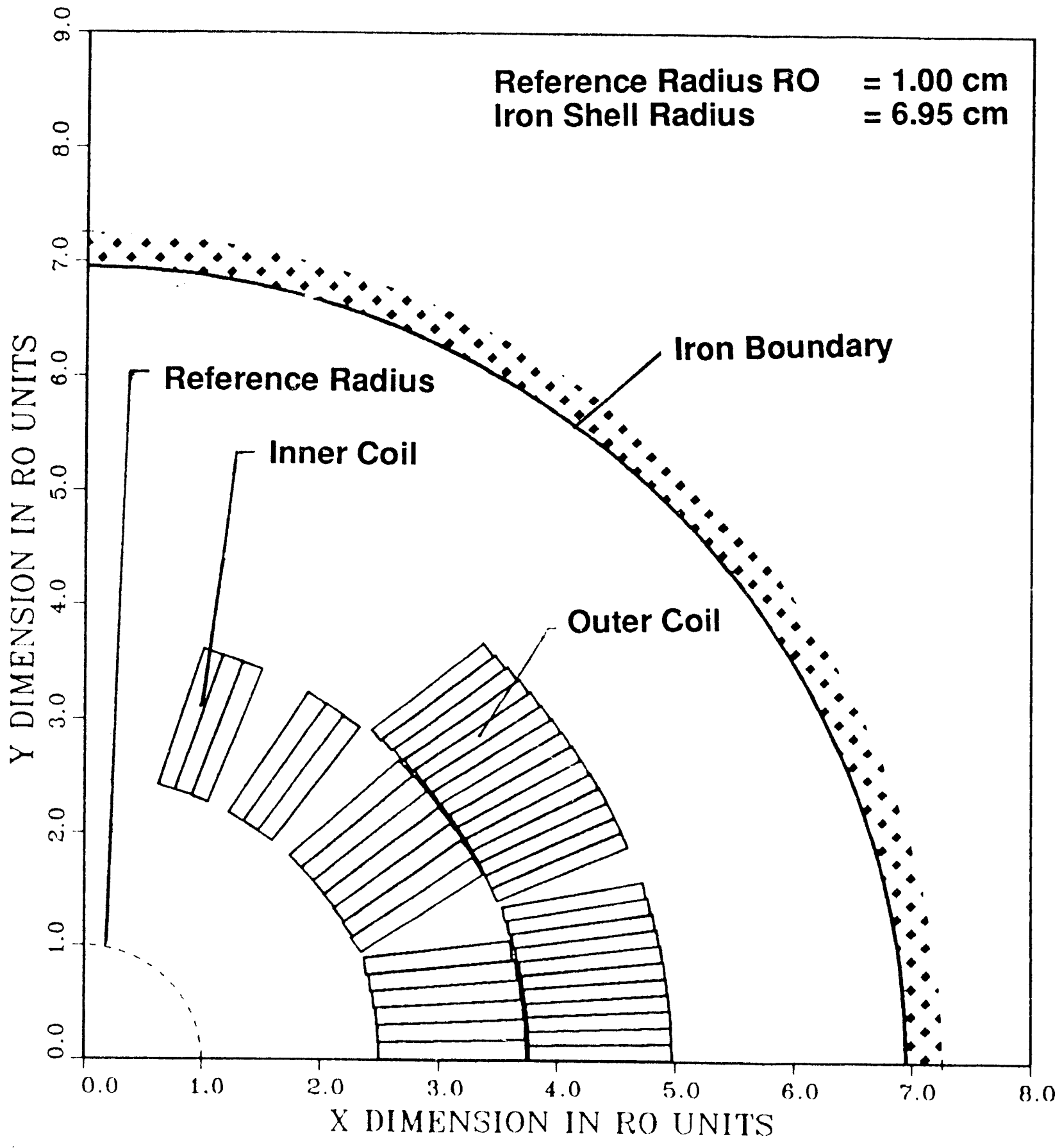


Figure 4

MAGNETIZATIUN SEXTUPOLE AND DECAPOLE RATIOS AS A FUNCTION OF CENTRAL. INDUCTION WITH A MINIMUM CYCLE INDUCTION OF 0.0.5 TESLA WITHOUT PASSIVE CORRECITION

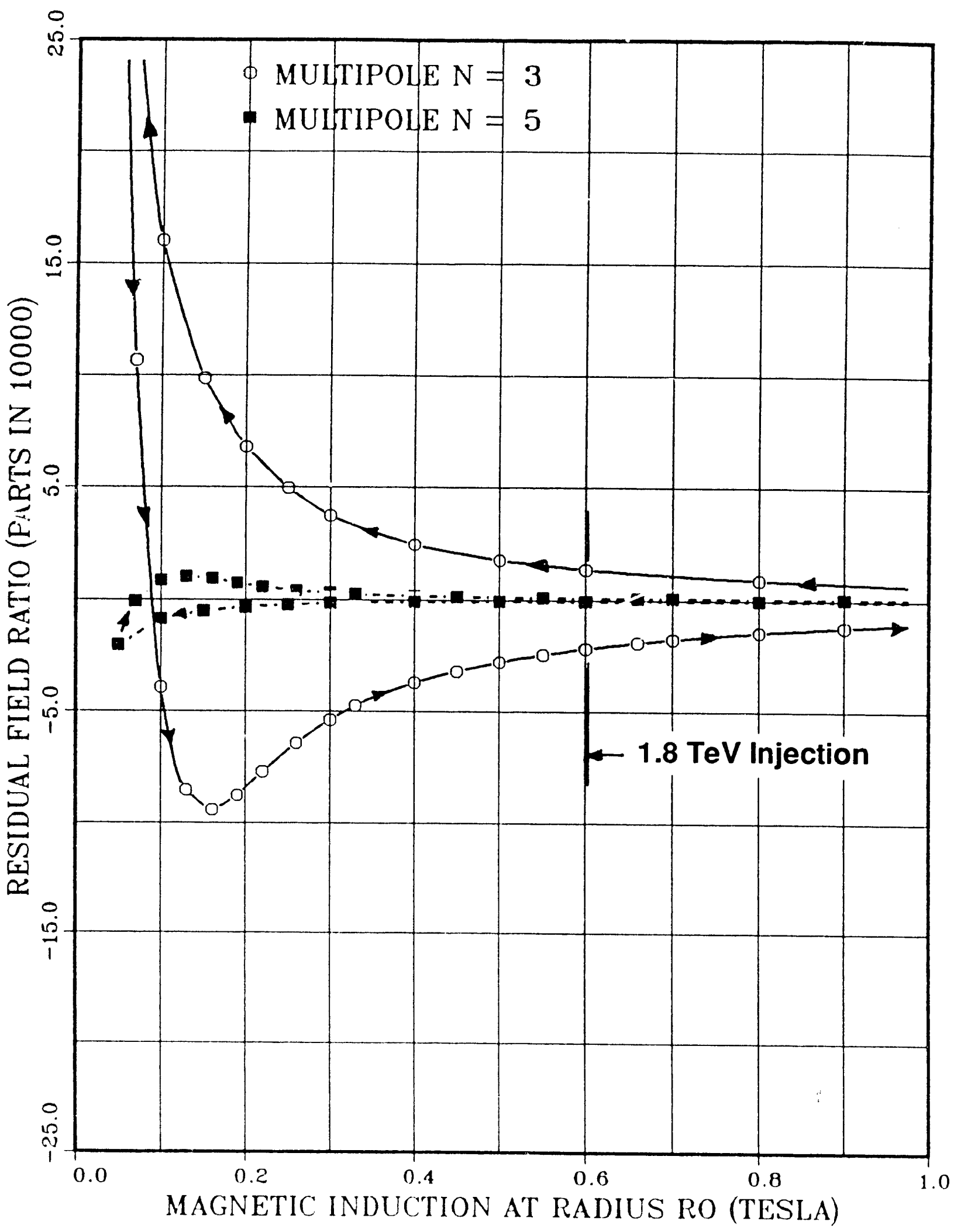


Figure 5

MAGNETIZATION SEXTUPOLE AND DECAPOLE RATIOS AS A FUNCTION OF CENTRAL INDUCTION WITH A MINIMUM CYCLE INDUCTION OF 0.25 TESLA WITHOUT PASSIVE CORRECTION

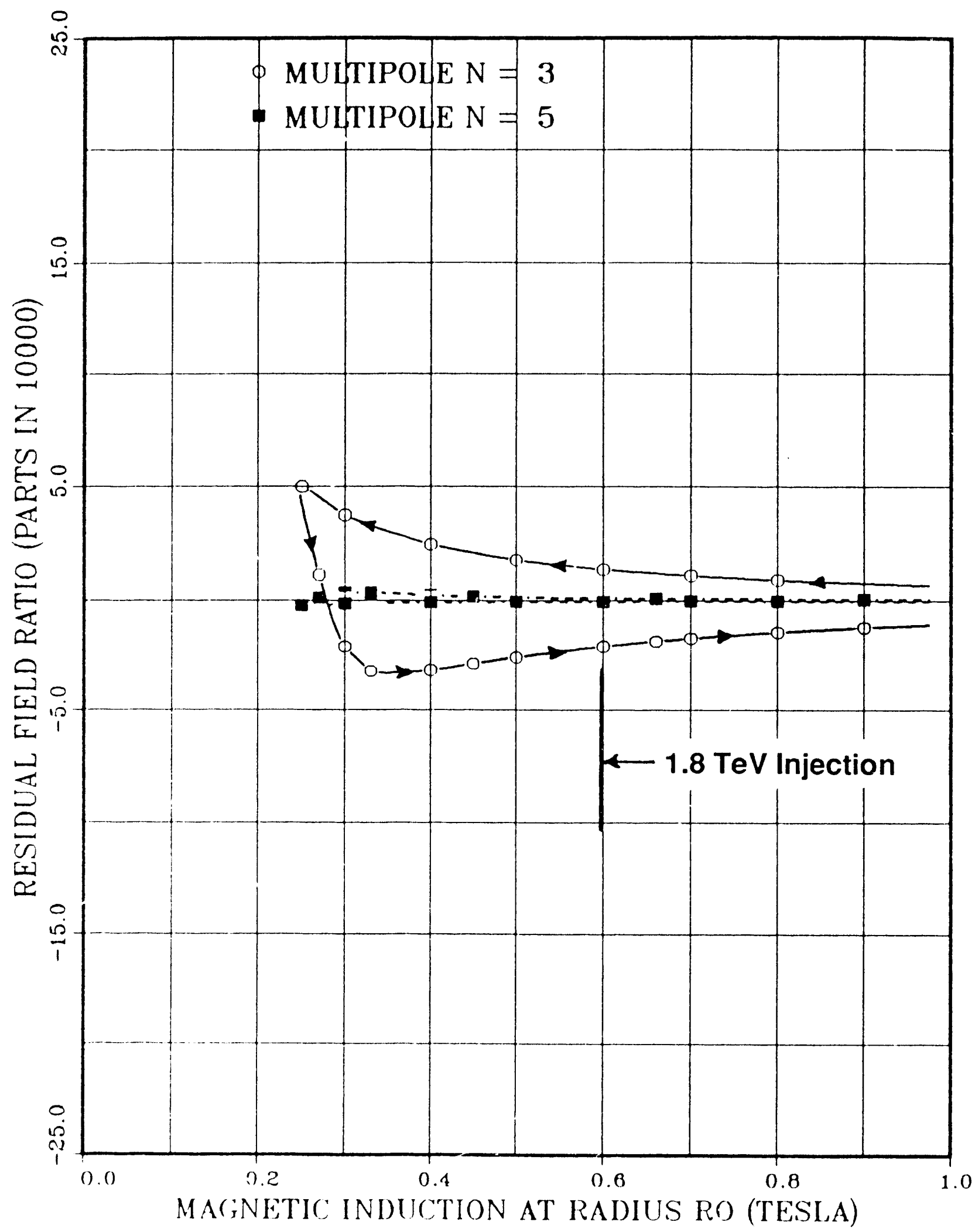


Table 3 compares the magnetization sextupole and decapole generated in the DX-201 dipole with and without 14 micron filaments in block 1 . (The case without correction has 6 micron filaments in block 1.) On can see that the injection sextupole is reduced over an order of magnitude at injection fields of 0.33 tesla ( $1 \mathrm{TeV}$ injection) on up. The magnetization decapole is increased almost a factor of four by increasing the filament diameter in block 1 from 6 microns to 14 microns. This increase in the decapole term may not be acceptable in the SSC. If one looks at the magnetization dipole in Table 4, one sees that the dipole term is reduced along with the sextupole term when the filament diameter in block 1 is increased to 14 microns. This reduction is nice but not necessary; the magnetization dipole can be compensated for by increasing the magnet current from 0.3 to 0.5 amperes.

Figure 7 shows the magnetization sextupole and decapole ratios as a function of central induction. One can see from the figure that the shape of the sextupole and decapole magnetization curve is changed by the larger filaments in block 1 . The open loop at the low field end of the curve is due to the fact that 14 micron filaments have a different penetration induction than do 6 micron filaments. The compensation of intrinsic magnetization is responsible for the bending of the magnetization curves in the negative direction at low values of the central field. When one compares Figure 7 with Figure 4 one sees that good sextupole correction is achieved at central inductions above 0.33 tesla. One can also see that correction of the sextupole also occurs when the field is decreasing as well as increasing. The field going down is somewhat over corrected because the passive correction was also designed to include the intrinsic superconductor magnetization when the central field is rising.

Table 5 shows the effect of changing the turnaround central induction on the passive correction achieved using 14 micron filaments in block 1 of the magnet. When the turn around induction is 0.05 tesla, the field is good from 0.33 tesla on up. When the turn around induction is 0.25 tesla, the field is good from 0.50 tesla on up. When the turn around induction is 0.50 tesla, the field is good from 0.70 tesla on up. Figure 8 shows the magnetization sextupole and decapole ratios as a function of central induction when the turn around induction is 0.25 tesla. One should compare Figure 8 with Figure 5. One can see from Table 5 and Figure 8 that one does not have the choice of changing the magnet cycle along with adding 14 micron filaments to block 1 . The injection field must be at least 0.2 tesla above the turn around field for this method of correction to be applied.

The advantages of using 14 micron filaments in block 1 of the SSC dipole to compensate for the magnetization sextupole are as follows:

1. The magnetization sextupole can be reduced an order of magnitude at injection for central inductions of 0.33 tesla or larger. The turn around induction must be at least 0.2 tesla lower than the injection induction.

2. The magnetization dipole is also reduced over a wide range of injection inductions provided the turn around field is at least 0.2 tesla lower that the injection induction. 
3. No extra superconductor is required in the magnet in order to make the correction of the magnetization sextupole.

4. The magnetization sextupole is reduced over a wide range of central inductions even when the the field is going down. Large filaments in block 1 do not simply shift the magnetization curve from negative to positive. The sextupole is not well compensated in the region where flux reversal occurs in the magnet superconductor.

5. The temperature sensitivity of the magnetization sextupole is reduced about an order of magnitude.

6. It appears that the flux creep decay of the magnetization sextupole will be reduced by the larger filaments in block 1 . The extent of this creep decay reduction is not known.

The cisadvaritages of increasing the filament diameter in block one of the dipole can be summarized as follows:

1. The magnetization decapole is increased by a factor of three to four by the larger filaments in block 1 . This increase in the magnetization decapole may be unacceptable to the SSC.

2. A third type of superconductor must be specified and tracked througin the procurement cycle.

3. Each SSC dipole magnet will require two more cable joints. (The number of cable joints per magnet will increase from three to five.)

4. Changes of the corrector design have a large impact on the dipole program. If changes of the filament diameter in block 1 are to be made, they should be made early in the dipole program

It is not clear whether the advantages of this method of passive correction outweigh the disadvantages. The increase in the magnetization decapole may be unacceptable unless that decapole is compensated for in another way. It may be more difficult to eliminate the magnetization sextupole flux creep in magnets which use this method of correction. 
Figure 6

A QUARTER SECTION OF THE DX-201

SSC FIVE CENTIMETER BORE DIPÓLE MAGNET

WITH LARGER FILAMENTS IN BLOCK ONE

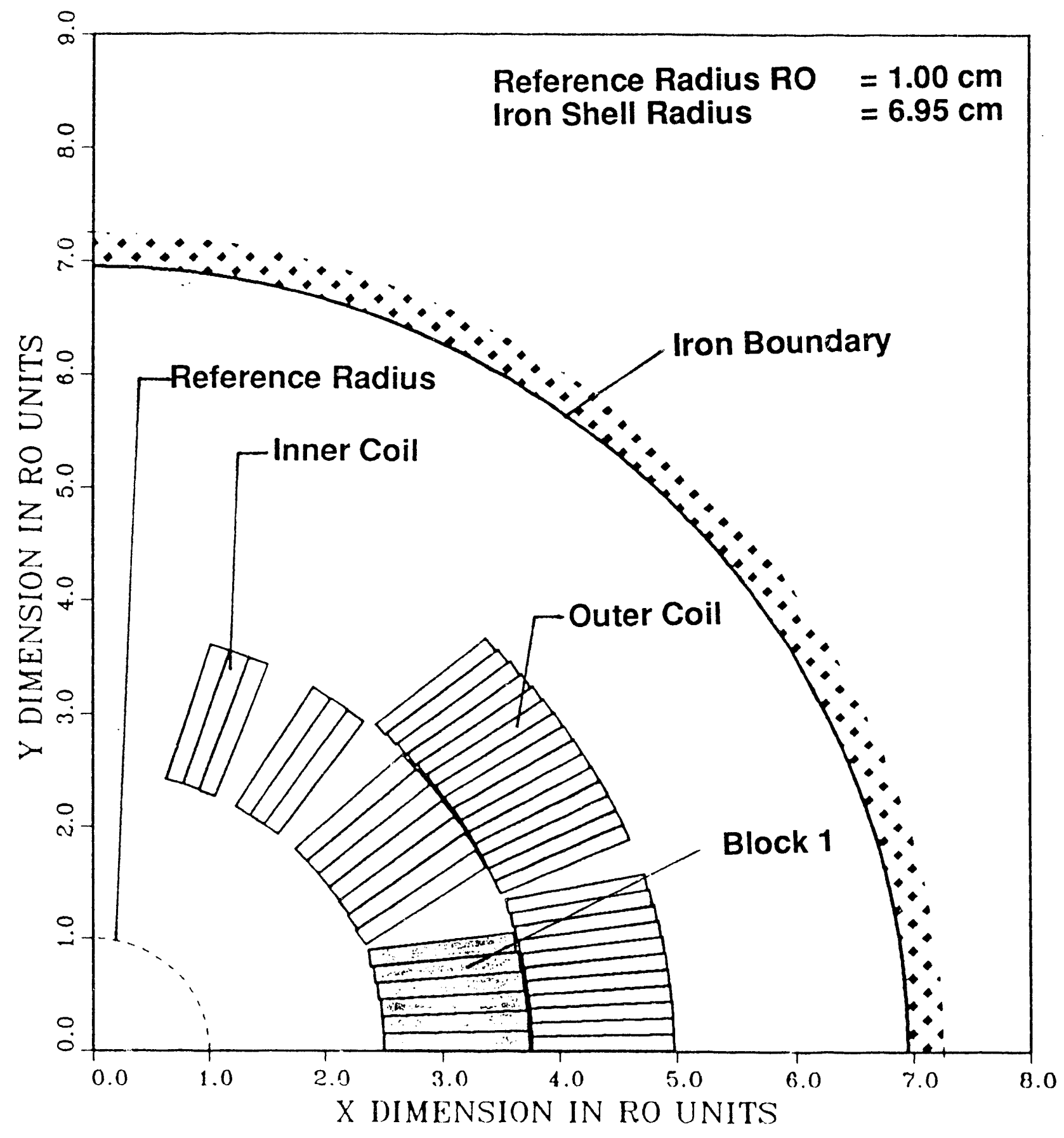


Table 3

CORRECTION OF MAGNETIZATION SEXTUPOLE IN THE SSC DIPOLE BY INCREASING THE SUPERCONDUCTOR FILAMENT DIAMETER IN BLOCK 1

\begin{tabular}{c|c|c|c|c|}
\multirow{2}{*}{$\begin{array}{c}\text { Central } \\
\text { Induction } \\
(\mathrm{T})\end{array}$} & \multicolumn{3}{c}{ Uncorrected Magnet } & \multicolumn{3}{c}{ Corrected Magnet } \\
\hline 0.20 & $\mathrm{~N}=3$ & $\mathrm{~N}=5$ & $\mathrm{~N}=3$ & $\mathrm{~N}=5$ \\
\hline 0.25 & -8.43 & 0.68 & -8.93 & 0.68 \\
0.33 & -6.71 & 0.45 & -3.63 & 0.85 \\
0.40 & -4.72 & 0.25 & -0.45 & 0.75 \\
0.45 & -3.69 & 0.18 & 0.03 & 0.60 \\
0.50 & -3.17 & 0.15 & 0.07 & 0.51 \\
0.55 & -2.75 & 0.12 & 0.06 & 0.44 \\
0.60 & -2.42 & 0.10 & 0.03 & 0.38 \\
0.66 & -2.15 & 0.09 & 0.00 & 0.34 \\
0.70 & -1.88 & 0.08 & -0.02 & 0.29 \\
0.80 & -1.74 & 0.07 & -0.03 & 0.27 \\
0.90 & -1.44 & 0.06 & -0.04 & 0.22 \\
1.00 & -1.22 & 0.05 & -0.04 & 0.19 \\
& -1.04 & 0.04 & -0.03 & 0.16 \\
\hline
\end{tabular}

The uncorrected magnet has 6 micron filament superconductor in all ccil blocks. The corrected magnet has 14 micron filaments in block 1 and 6 micron filaments in the other five magnet coil blocks.

The magnet central induction cycle goes from $6.6 \mathrm{~T}$ to $0.05 \mathrm{~T}$ to the central induction given in the table. 
Table 4

CHANGES OF THE MAGNETIZATION DIPOLE IN THE SSC DIPOLE BY INCREASING THE SUPERCONDUCTOR FILAMENT DIAMETER IN BLOCK 1

\begin{tabular}{|c|c|c|}
$\begin{array}{c}\text { Central } \\
\text { Induction } \\
(\mathrm{T})\end{array}$ & \multicolumn{2}{c|}{ Magnetization Dipole (gauss) } \\
\hline 0.20 & Uncorrected Magnet & Corrected Magnet \\
\hline 0.25 & -5.17 & -5.80 \\
0.33 & -5.06 & -2.97 \\
0.40 & -4.70 & -0.42 \\
0.45 & -4.47 & 0.18 \\
0.50 & -4.36 & 0.25 \\
0.55 & -4.22 & 0.23 \\
0.50 & -4.09 & 0.18 \\
0.66 & -3.96 & 0.12 \\
0.70 & -3.83 & 0.06 \\
0.80 & -3.75 & 0.02 \\
0.90 & -3.56 & -0.01 \\
1.00 & -3.37 & -0.01 \\
& -3.19 & -0.01 \\
\hline
\end{tabular}

The uncorrected magnet has 6 micron filament superconductor in all coil blocks. The corrected magnet has 14 micron filaments in block 1 and 6 micron filaments in the other five magnet coil blocks.

The magnet central induction cycle goes from $6.6 \mathrm{~T}$ to $0.05 \mathrm{~T}$ to the central induction given in the table. 
Figure 7

MAGNETIZATION SEXTUPOLE AND DECAPOLE RATIOS AS A FUNCTION OF CENTRAL INDUCTION WITH A MINIMUM CYCLE INDUCTION OF 0.05 TESLA WITH 14 MICRON FILAMENTS IN BLOCK 1

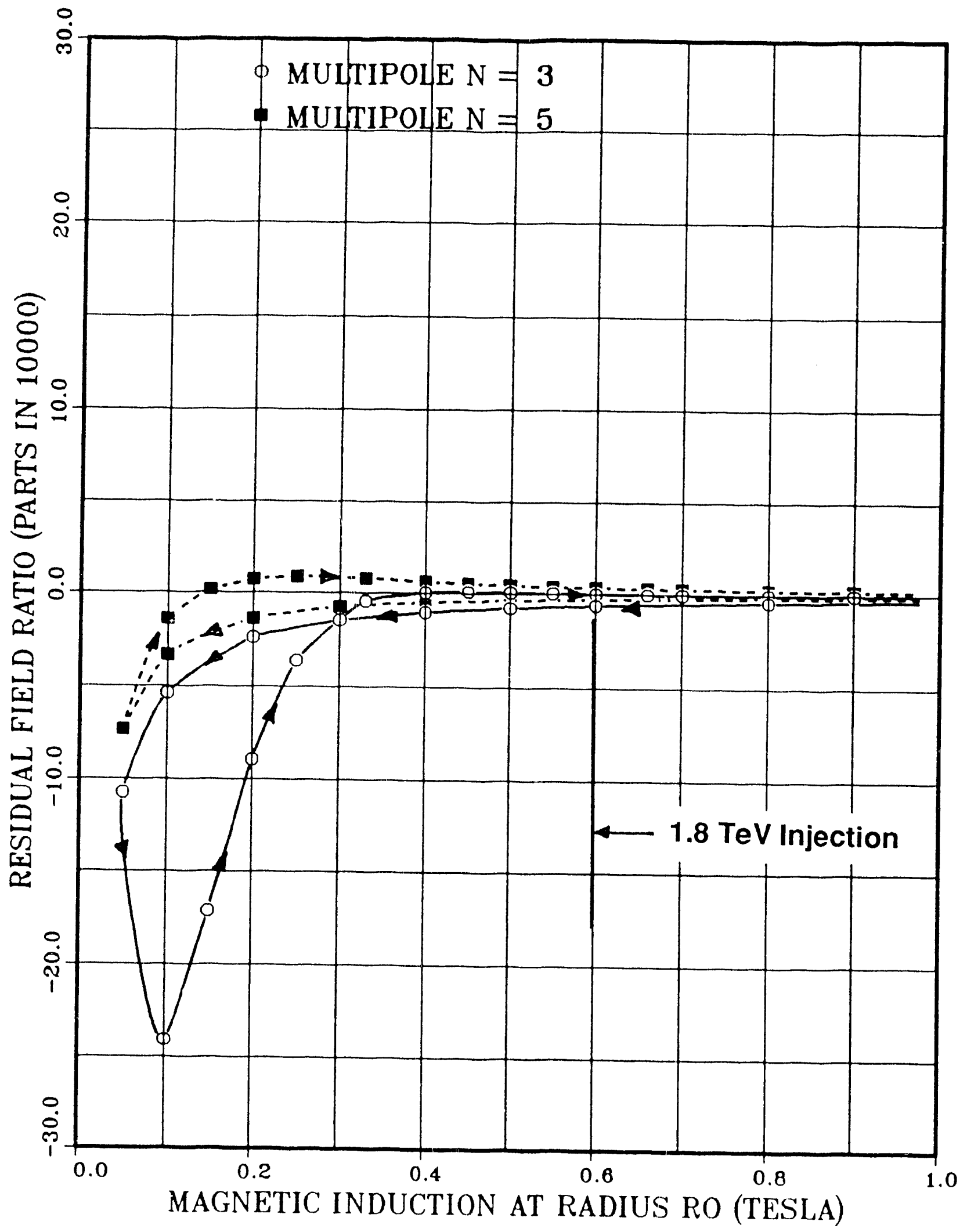


Table 5

THE EFFECT OF CHANGING THE TURN AROUND CENTRAL INDUCTION ON THE MAGNETIZATIONS SEXTUPOLE IN A SSC DIPOLE CORRECTED WITH 14 MICRON FILAMENTS IN BLOCK 1 OF THE COIL

\begin{tabular}{|c|c|c|c|}
\hline \multirow{2}{*}{$\begin{array}{l}\text { Central } \\
\text { Induction } \\
\text { (T) }\end{array}$} & \multicolumn{3}{|c|}{ Magnetization Sextupole Ratio (units) } \\
\hline & $\mathrm{Bo}=0.05 \mathrm{~T}$ & $\mathrm{Bo}=0.25 \mathrm{~T}$ & $\mathrm{Bo}=0.50 \mathrm{~T}$ \\
\hline $\begin{array}{l}0.25 \\
0.33 \\
0.40 \\
0.45 \\
0.50 \\
0.55 \\
0.60 \\
0.66 \\
0.70 \\
0.80 \\
0.90 \\
1.00\end{array}$ & $\begin{array}{r}-3.63 \\
-0.45 \\
0.03 \\
0.07 \\
0.06 \\
0.03 \\
0.00 \\
-0.02 \\
-0.03 \\
-0.04 \\
-0.04 \\
-0.03\end{array}$ & $\begin{array}{l}-1.82 \\
-5.31 \\
-1.77 \\
-0.61 \\
-0.18 \\
-0.04 \\
-0.01 \\
-0.01 \\
-0.02 \\
-0.03 \\
-0.03 \\
-0.03\end{array}$ & $\begin{array}{l}-. . .- \\
-. .- \\
-0.76 \\
-2.57 \\
-1.25 \\
-0.31 \\
-0.11 \\
-0.01 \\
-0.02 \\
-0.02\end{array}$ \\
\hline
\end{tabular}

The magnet has 6 micron filament superconductor in all coil blocks except block 1. The copper to superconductor ratio for the inner layer in all blocks is 1.5 to 1 . The copper to supper conductor ratio for the outer layer in all blocks is 1.8 to 1 . The corrected magnet has 14 micron filaments in the cable in block 1 of the coil.

The magnet central Induction cycle goes from 6.6 $\mathrm{T}$ to Bo to the central induction given in the table. 
Figure 8

MAGNETIZATION SEXTUPOLE AND DECAPOLE RATIOS AS A FUNCTION OF CENTRAL INDUCTION WITH A MINIMUM C.YCLE INDUCTION OF 0.25 TESLA WITH 14 MICRON FILAMENTS IN BLOCK 1

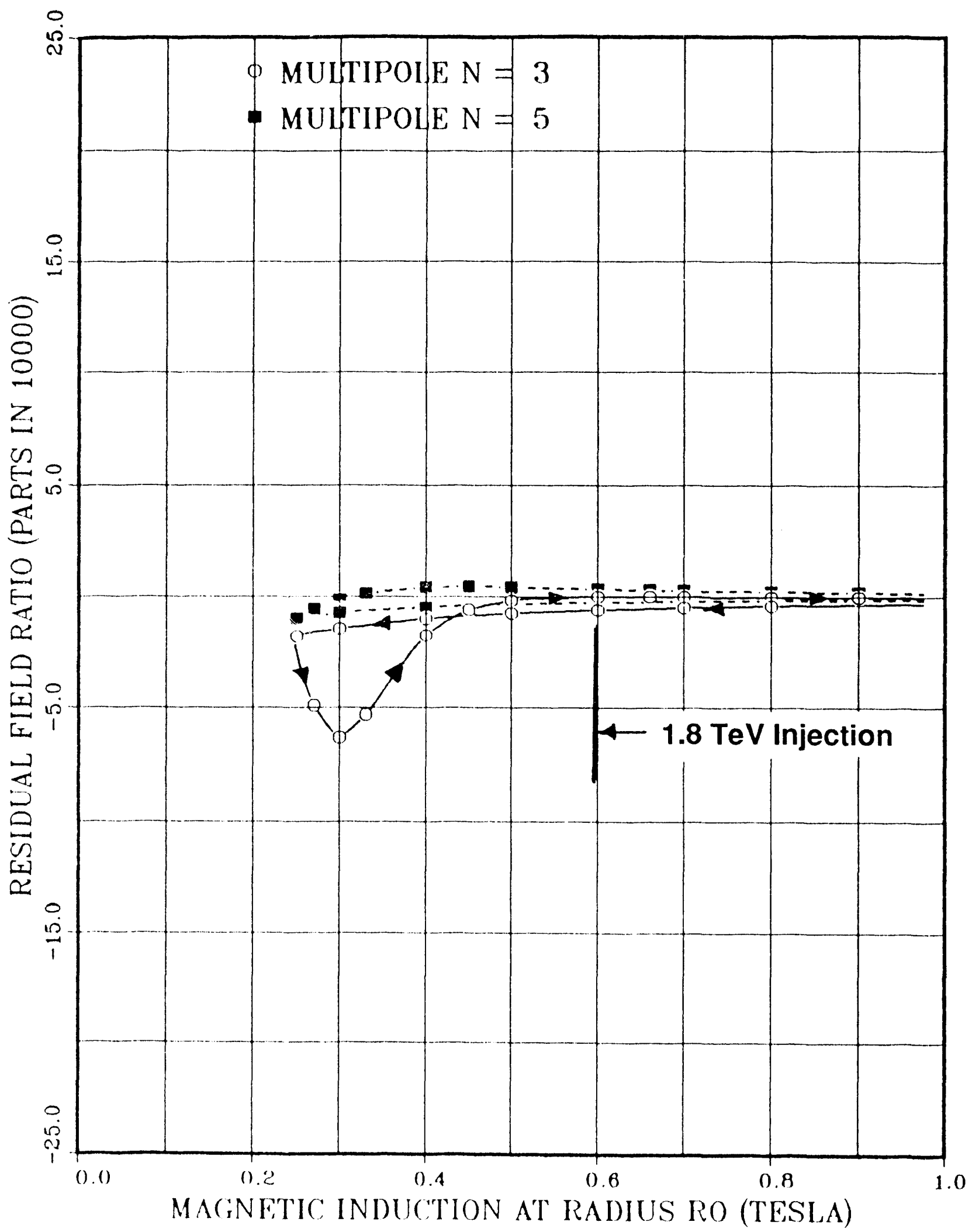




\section{THE ELIMINATION OF MAGNETIZATION SEXTUPOLE AND DECAPOLE BY ADDING PASSIVE SUPERCONDUCTOR TO THE INNER BORE OF THE DIPOLE}

This method of passive correction using superconductor on the inner coil bore is not new. This method of correction was proposed by Brown and Fisk of Fermilab in 1984 12. Studies by LBL in 1987 demonstrated that this method of magnetization sextupole and decapole correction could be applied to dipole magnets with filament diameters as large as 24 microns. The method of passive correction described here for the DX-201 dipole has been experimentally verified for both 40 and 50 millimeter bore dipoles at Fermilab 17 and LBL 18. The LBL experiments showed that the corrector conductor can have a filament diameter which is four times larger that the filaments which are in the dipole cable. The LBL experiments demonstrated that good correction can be achieved if one knows the critical current density of the magnet superconductor and the corrector superconductor at 5 tesla and $4.2 \mathrm{~K}$. The LBL experiments further demonstrated that the flux creep decay and related decays can be at least partially compensated for by the use of passive superconductor inside the dipole magnet bore ${ }^{19}$.

The correctors shown in Figure 9 were chosen because they represent the thickest layer of corrector conductors which can reasonably be put into the space inside the dipole coils. The correctors shown in Figure 9 are represented by squares. Each square represents a single round wire. The packing factor for each square is 0.785 . The midplane angle of 2 degrees was chosen based on the LBL experimental program. At the time, the corrector design shown in Figure 9 was selected, it was felt that the optimum filament diameter had to be between 9 and 10 microns. This turned out to be incorrect. The filament diameter chosen for the correctors shown in Figure 9 was 12 microns and the copper to superconductor ratio chosen was $i$ to 1 . The 12 micron filament diameter chosen turned out to be nearly optimum. Because the corrector conductor carries no transport current, the copper to supierconductor ratio in the corrector conductor can be made as low as possible provided the space between the filaments is larger than 1.2 microns (in order to avoid proximity coupling 20 ).

Table 6 compares the magnetization sextupole and decapole ratios for the uncorrected DX-201 dipole (See Figure 3) and the DX-201 dipole corrected with passive superconductor inside the bore (See Figure 9). Table 7 compare the magnetization dipole fields for the uncorrected and corrected DX-201 dipoles. From Table 6, one can see that the passive correctors reduced the magnetization sextupole by over an order of magnitude over a range of injection central inductions from 0.33 tesla on up. The magnetization decapole was reduced about a factor of three over the same range of injection central inductions. The 2 degree midplane angle which reduced the magnetization decapole increased the magnetization dipole about 15 percent. The increased magnetization dipole is not of concern. It can be compensated for by increasing the current in the magnet from 0.3 to 0.6 amperes depending on where one is in the magnet cycle. 
Table 7 shows the effect of changing the turn around field on the magnetization sextupole at injection with the correctors in as shown in Figure 9. Correction using 12 micron correction conductors is much more tolerant to changes in the magnet cycle than is the previous type of correction which increases the filament diameter in block 1. This fact is illustrated by Figures 10 and 11. The corrected field shown in Figure 10 should be compared to the uncorrected field shown in Figure 4. One can see that the magnetization sextupole is very nearly zero from a central induction of 0.3 tesla on up when the turn around central induction is 0.05 tesla. Evon in the multiple flux penetration region, the magnetization sextupole is much more closed in Figure 10 than it is in Figure 4. The bend of the magnetization sextupole to negative values in Figure 10 is probably due to the intrinsic magnetization of the superconductor which has been over compensated for at low fields. The corrected field in Figure 11 should be compared to the uncorrected field shown in Figure 5 . The use of 12 micron correctors in the bore of the dipole is improved at higher turn around fields. The use of the 12 micron filament correctors inside the magnet bore permits one to greatly alter the magnet cycle and get correction of the magnetization sextupole and decapole by a factor of five or more. The amount of additional superconductor required to get the levels of correction shown in Figures 10 and 11 represents about 2.7 percent of the superconductor in the DX-201 SSC dipole magnet.

The advantages of using 12 micron filament passive correctors inside of the SSC dipole to compensate for the magnetization sextupole are as follows:

1. The magnetization sextupole can be reduced at injection for central inductions of 0.30 tesla or larger. (The reduction over this field range is over an order of magnitude.) The correction is much less sensitive to the turn around induction.

2. The magnetization decapole is also reduced over the same wide range of injection inductions. The turn around induction is not an important factor for decapole correction.

3. The magnetization sextupole is reduced over a wide range of central inductions even when the the field is going down. The corrector wires inside the magnet bore do not simply shift the magnetization curve from negative to positive.

4. At central inductions above 0.30 tesla the sextupole is reasonably well compensated for in the region where flux reversal occurs in the magnet superconductor. This means that the magnet cycle can be changed in order to reduce the flux _. cep decay at injection.

5. The temperature sensitivity of the magnetization sextupole is reduced over an order of magnitude. LBL experimental measurements showed a reduction of temperature sensitivity by about a factor of thirty. 
6. It appears that the flux creep decay of the magnetization sextupole will be reduced by the passive corrector in the magnet bore. LBL experiments have shown that the flux creep decay can be reduced a factor of three. The ability to alter the magnet cycle should permit further reductions in the flux creep decay.

7. Changes of the corrector design can be made without altering the basic design of the SSC dipole. The correctors can be made by a different company than the company which makes the dipole magnets. The assembly of the corrector into the dipole is made by the company which manufactures the dipole magnet. The decision to use this type of corrector can be made later in the SSC dipole program.

The disadvantages of the separate corrector in the inner bore of the dipole can be summarized as follows:

1. The passive corrector require extra radial space inside of the dipole magnet. While the correctors are not adversely affected by synchrotron radiation heating of the dipole magnet, their presence may adversely affect the removal of the synchrotron radiation heat from the magnet bore tube. The extra radial space (about 2 millimeters) has to be considered in the design.

2. About 2.7 percent more superconductor is required in the dipole magnet in order to passively correct the magnetization sextupole and decapole. If one can increase the filament diameter in the correctors, less superconductor is required to do the correction.

3. A third type of superconductor must be specified and tracked through the procurement cycle.

It is clear that this method of correction is superior to increasing the diameter of the superconductor filaments in block 1 of the dipole magnets. This method of correction greatly reduces both the magnetization sextupole and decapole at injection. The reduction of magnetization sextupole flux creep decay appears to be more certain with the use of separate correctors in the inner bore of the dipole magnet. 
Figure 9

A QUARTER SECTION OF THE DX-201

SSC FIVE CENTIMETER BORE DIPOLE MAGNET

WITH 12 MICRON PASSIVE SUPERCONDUCTOR IN THE BORE

(Midplane Angle $=2$ degrees, $\mathrm{Cu}$ to $\mathrm{S} / \mathrm{C}$ Ratio $=1.0$ )

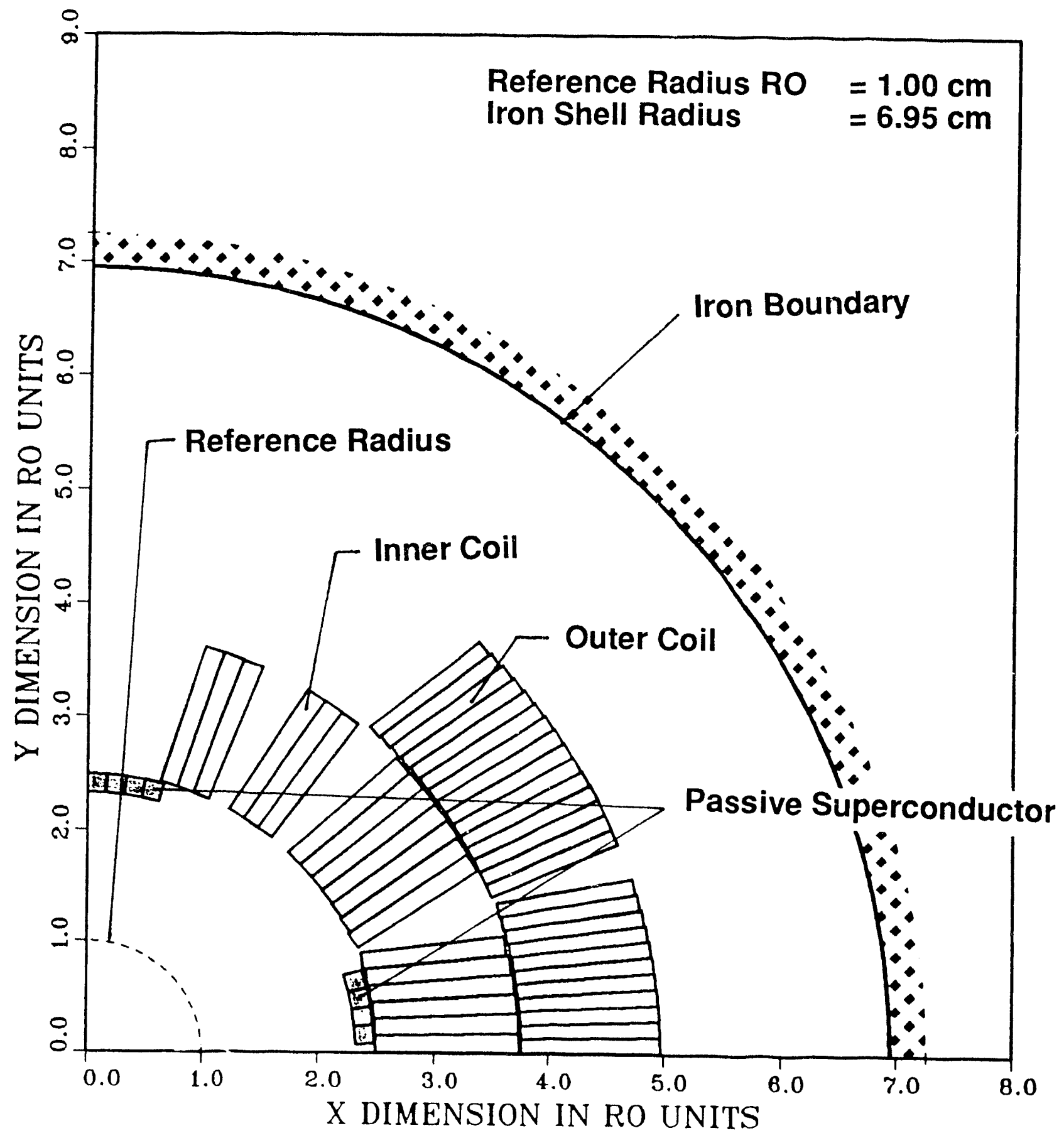


Table 6

CORRECTION OF MAGNETIZATION SEXTUPOLE IN THE SSC DIPOLE BY INSTALLING PASSIVE SUPERCONDUCTING WIRES INSIDE THE DIPOLE COIL (12. micron filaments, 2 degree midplane angle)

\begin{tabular}{|c|c|c|c|c|}
\hline \multirow{3}{*}{$\begin{array}{l}\text { Central } \\
\text { Induction } \\
\text { (T) }\end{array}$} & \multicolumn{4}{|c|}{ Magnetization Multipole Ratios (units) } \\
\hline & \multicolumn{2}{|c|}{ Uncorrected Magnet } & \multicolumn{2}{|c|}{ Corrected Magnet } \\
\hline & $\mathbf{N}=\mathbf{3}$ & $N=5$ & $\mathbf{N}=\mathbf{3}$ & $N=5$ \\
\hline $\begin{array}{l}0.20 \\
0.25 \\
0.33 \\
0.40 \\
0.45 \\
0.50 \\
0.55 \\
0.60 \\
0.66 \\
0.70 \\
0.80 \\
0.90 \\
1.00\end{array}$ & $\begin{array}{l}-8.43 \\
-6.71 \\
-4.72 \\
-3.69 \\
-3.17 \\
-2.75 \\
-2.42 \\
-2.15 \\
-1.88 \\
-1.74 \\
-1.44 \\
-1.22 \\
-1.04\end{array}$ & $\begin{array}{l}0.68 \\
0.45 \\
0.25 \\
0.18 \\
0.15 \\
0.12 \\
0.10 \\
0.09 \\
0.08 \\
0.07 \\
0.06 \\
0.05 \\
0.04\end{array}$ & $\begin{array}{r}0.17 \\
0.80 \\
0.12 \\
0.00 \\
-0.06 \\
-0.11 \\
-0.10 \\
-0.08 \\
-0.07 \\
-0.07 \\
-0.07 \\
-0.07 \\
-0.07\end{array}$ & $\begin{array}{l}0.43 \\
0.22 \\
0.10 \\
0.07 \\
0.05 \\
0.04 \\
0.04 \\
0.03 \\
0.03 \\
0.03 \\
0.02 \\
0.02 \\
0.01\end{array}$ \\
\hline
\end{tabular}

The uncorrected magnet has 6 micron filament superconductor in all coil blocks. The corrected magnet has eight strands of $1.616 \mathrm{~mm}$ diameter conductor symmetrically arranged about each magnet pole and eight strands of $1.616 \mathrm{~mm}$ diameter conductor symmetrically arranged about the left and right magnet mid plane. The $1.616 \mathrm{~mm}$ strands have a copper to superconductor ratio of 1 to 1 and the filament diameter is 12 microns. The midplane angle of the corrector is 2 degrees. The corrector superconductor is $\mathbf{2 . 7 3}$ percent of the superconductor in the dipole coils.

The magnet central induction cycle goes from 6.6 $\mathrm{T}$ to $0.05 \mathrm{~T}$ to the central induction given in the table. 
Table 7

\section{CHANGES OF THE MAGNETIZATION DIPOLE IN THE SSC DIPOLE BY BY INSTALLING PASSIVE SUPERCONDUCTING WIRES INSIDE THE DIPOLE COIL \\ (12 micron filaments, 2 degree midplane angle)}

\begin{tabular}{|c|c|c|}
$\begin{array}{c}\text { Central } \\
\text { Induction } \\
(T)\end{array}$ & \multicolumn{2}{c|}{ Magnetization Dipole (gauss) } \\
\hline 0.20 & Uncorrected Magnet & Corrected Magnet \\
\hline 0.25 & -5.17 & -5.74 \\
0.33 & -5.06 & -5.68 \\
0.40 & -4.70 & -5.23 \\
0.45 & -4.47 & -4.96 \\
0.50 & -4.36 & -4.82 \\
0.55 & -4.22 & -4.66 \\
0.60 & -4.09 & -4.51 \\
0.66 & -3.96 & -4.37 \\
0.70 & -3.83 & -4.23 \\
0.80 & -3.75 & -4.14 \\
0.90 & -3.56 & -3.92 \\
1.00 & -3.37 & -3.71 \\
\hline
\end{tabular}

The uncorrected magnet has 6 micron filament superconductor in all coil blocks. The corrected magnet has eight strands of $1.616 \mathrm{~mm}$ diameter conductor symmetrically arranged about each magnet pole and eight strands of $1.616 \mathrm{~mm}$ diameter conductor symmetrically arranged about the left and right magnet mid plane. The $1.616 \mathrm{~mm}$ strands have a copper to superconductor ratio of 1 to 1 and the filament diameter is 12 microns. The midplane angle of the corrector is 2 degrees. The corrector superconductor is 2.73 percent of the superconductor in the dipole coils.

The magnet central induction cycle goes from $6.6 \mathrm{~T}$ to $0.05 \mathrm{~T}$ to the central induction given in the table. 
Figure 10

MAGNETIZATION SEXTUPOLE AND DECAPOLE RATIOS AS A FUNCTION OF CENTRAL INDUCTION WITH A MINIMUM CYCLE INDUCTION OF 0.05 TESLA WITH 12 MICRON PASSIVE CORRECTORS

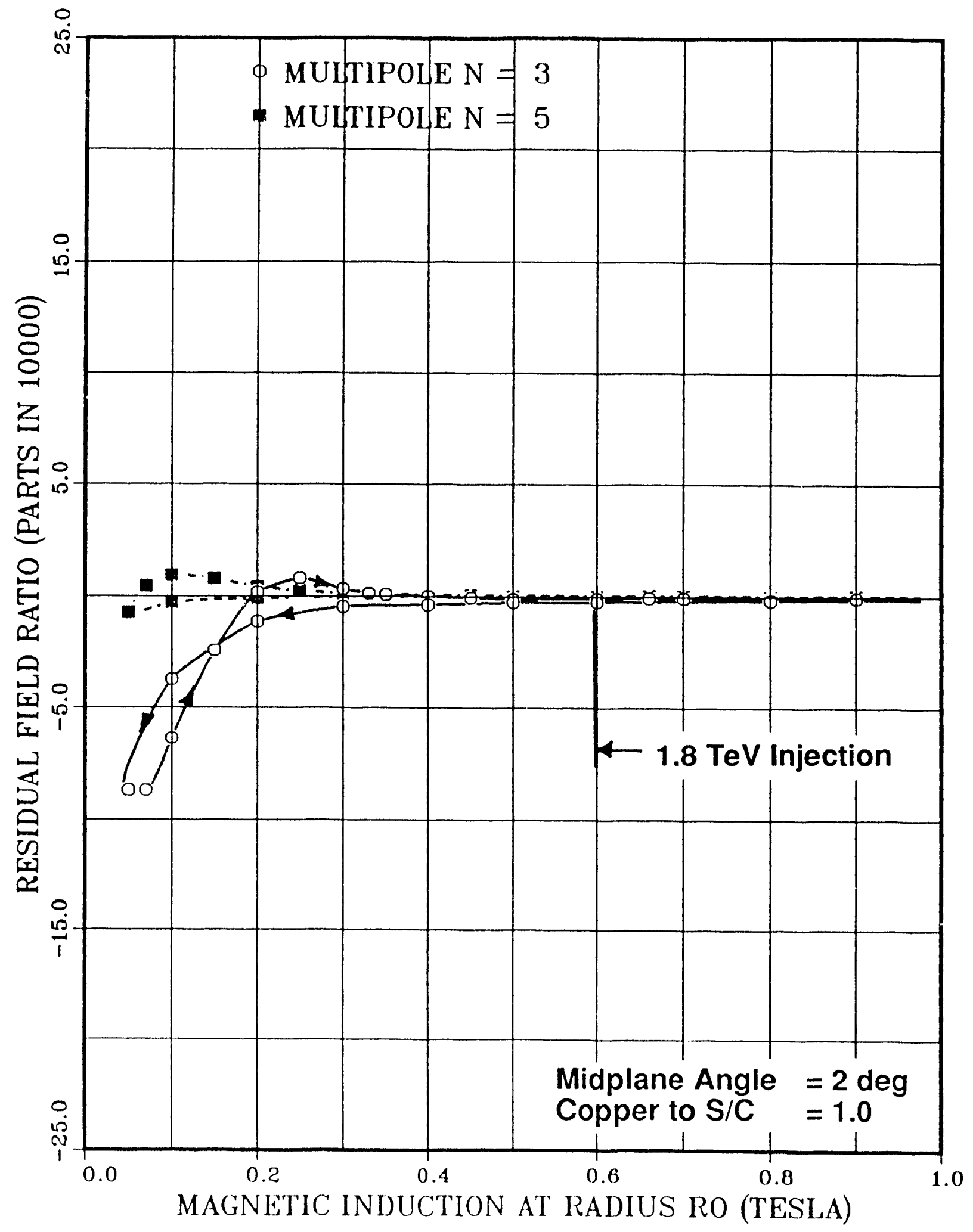


Table 8

THE EFFECT OF CHANGING THE TURN AROUND

CENTRAL INDUCTION ON THE MAGNETIZATIONS

SEXTUPOLE IN A SSC DIPOLE CORRECTED WITH

PASSIVE SUPERCONDUCTING WIRES INSIDE THE COIL

(12 micron filaments, 2 degree midplane angle)

\begin{tabular}{|c|c|c|c|}
\hline \multirow{2}{*}{$\begin{array}{l}\text { Central } \\
\text { Induction } \\
\text { (T) }\end{array}$} & \multicolumn{3}{|c|}{ Magnetization Sextupole Ratio (units) } \\
\hline & $\mathrm{BO}=0.05 \mathrm{~T}$ & $\mathrm{Bo}=0.25 \mathrm{~T}$ & $\mathrm{BO}=0.50 \mathrm{~T}$ \\
\hline $\begin{array}{l}0.25 \\
0.33 \\
0.40 \\
0.45 \\
0.50 \\
0.55 \\
0.60 \\
0.66 \\
0.70 \\
0.80 \\
0.90 \\
1.00\end{array}$ & $\begin{array}{r}0.80 \\
0.12 \\
0.00 \\
-0.06 \\
-0.11 \\
-0.10 \\
-0.08 \\
-0.07 \\
-0.07 \\
-0.07 \\
-0.07 \\
-0.07\end{array}$ & $\begin{array}{r}-0.62 \\
-0.12 \\
0.45 \\
0.21 \\
0.05 \\
-0.01 \\
-0.03 \\
-0.05 \\
-0.05 \\
-0.06 \\
-0.07 \\
-0.07\end{array}$ & $\begin{array}{r}-.-.- \\
-.-.- \\
-0 .- \\
-0.26 \\
-0.20 \\
0.21 \\
0.16 \\
0.08 \\
-0.02 \\
-0.05 \\
-0.06\end{array}$ \\
\hline
\end{tabular}

The uncorrected magnet has 6 micron filament superconductor in all coil blocks. The corrected magnet has eight strands of $1.616 \mathrm{~mm}$ diameter conductor symmetrically arranged about each magnet pole and eight strands of $1.616 \mathrm{~mm}$ diameter conductor symmetrically arranged about the left and right magnet mid plane. The $1.616 \mathrm{~mm}$ strands have a copper to superconductor ratio of 1 to 1 and the filament diameter is 12 microns. The midplane angle of the corrector is 2 cegrees. The corrector superconductor is 2.73 percent of the superconductor in the dipole coils.

The magnet central Induction cycle goes from 6.6 $\mathrm{T}$ to Bo to the central induction given in the tabie. 
Figure 11

MAGNETIZATION SEXTUPOLE AND DECAPOLE RATIOS AS A FUNCTION OF CENTRAL INDUCTION WITH A MINIMUM CYCLE INDUCTION OF 0.25 TESLA WITH 12 MICRON PASSIVE CORRECTORS

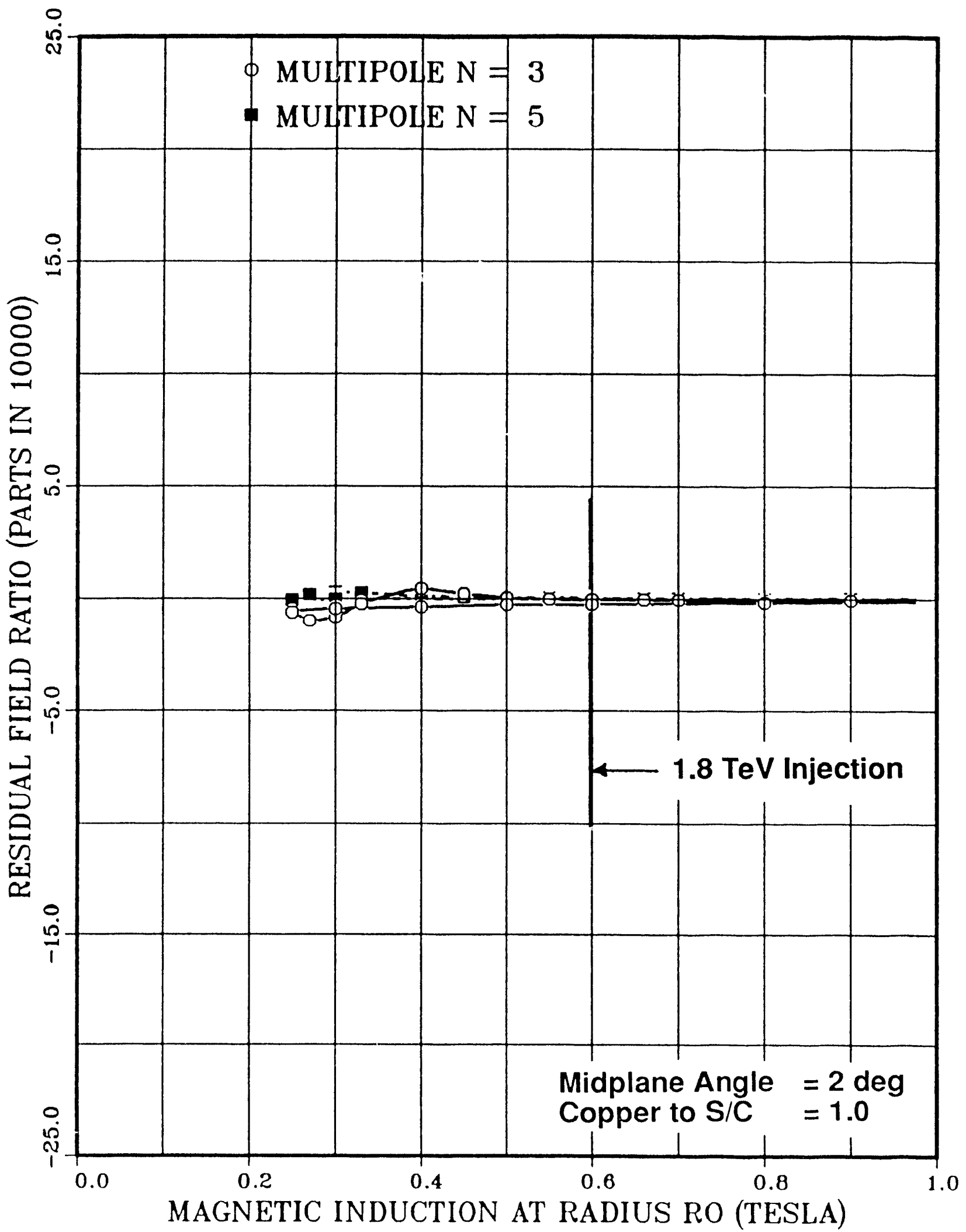




\section{THE EFFECT OF FILAMENT DIAMETER AND MIDPLANE ANGLE ON THE CORRECTION OF MAGNETIZATION SEXTUPOLE AND DECAPOLE IN THE SSC DIPOLE USING PASSIVE SUPERCONDUCTOR CORRECTORS IN THE. MAGNET BORE}

The use of correctors with 12 micron filaments in the inner bore of the DX-201 SSC dipole does a good job of reducing the magnetization sextupole and decapole at injection. The magnetization decapole was not completely eliminated by the correction elements shown in Figure 9. The decapole term is sensitive to the mid plane angle of the correctors at the dipole midplane. (The correctors at the pole should remain against the pole.) If one increases the corrector midplane angle from 2 degrees to 3 degrees by using a 2.53 millimeter shim between the upper and lower midplane correctors instead of a 1.68 millimeter shim, one can reduce the decapole due to magnetization by over an order of magnitude instead of a factor two to three. This midplane angle would apply to a wide variety of passive correctors which cover an angle at the pole and the midplane of about 15 degrees. (Correctors which have a 15 degree angle are nearly optimum.) In order to show the effect of filament diameter on the correction of the magnetization sextupole and decapole, correctors with filament diameters of 6 microns, 9.5 microns, 12 microns, 20 microns and 27 microns are presented.

The 6 micron filament passive correctors is shown in Figure 12. The correctors can be round wires with a diameter of 3.232 millimeters and a copper to superconductor ratio of 1.3. The correction of the magnetization sextupole and decapole is illustrated in Table 9 and Figure 13. (Figure 13 should be compared with Figure 5 in order to see the degree of magnetization correction.) Good correction of the magnetization sextupole is achieved for injection central inductions from 0.26 tesla on up. The effect of intrinsic magnetization is fully corrected by the correctors at all fields going up or down. The shape of the magnetization sextupole curve shown in Figure 13 is due to the differences in the penetration of the filament is various parts of the dipole coils and the correctors. In order to be able to reduce the area of the low field magnetization loop shown in Figure 13, the filament diameter within the correctors inside the magnet bore must be increased. The decapole magnetization curve has nearly been eliminated by the 6 micron filament corrector on the inside of the magnet bore.

The 9.5 micron filament passive correctors is shown in Figure 14. The reason 9.5 micron filaments were chosen is that the average field in the dipole conductors is about 65 percent of the field in the correctors. The correctors shown in Figure 14 can be round wires with a diameter of 2.155 millimeters and a copper to superconductor ratio of 1.1. The correction of the magnetization sextupole and decapole is illustrated in Table 10 and Figure 15. (Figure 15 should be compared with Figure 5 and Figure 13 in order to see the degree of magnetization correction.) Good correction of the magnetization sextupole is achieved for injection central inductions from 0.30 tesla on up. The effect of intrinsic magnetization is not fully currected by the correctors at all fields going up or down, so additional superconductor was put into the correctors. The magnetization sextupole curve shown in Figure 15 is negative at low central inductions because of the fact that the intrinsic magnetization is over compensated for by the passive correctors. The area of the magnetization sextupole loop at low fields shown in Figure 15 has been reduced, but not enough $A$ further increase in the filament diameter is required. The decapole magnetization curve shown in Figure 15 is a little larger than the magnetization decapole loop shown in Figure 13. 
The 12 micron filament passive corrector case is shown in Figure 16 . Figure 16 is identical to Figure 9 except the midplane angle is 3 degrees instead of 2 degrees. The copper to superconductor ratio in this case is 0.9 instead of 1.0 because the 3 degree midplane angle in the lower correctors produces about 4 percent less sextupole correction than the 2 degree midplane angle correctors. Increasing the amount of superconductor by 5 percent compensates for the effect of the larger midplane angle. The correctors shown in Figure 16 can be round wires with a diameter of 1.616 millimeters. The correction of the magnetization sextupole and decapole is illustrated in Table 11 and Figure 17. (Figure 17 should be compared with Figure 5 and Figure 9 in order to see the degree of magnetization correction.) Good correction of the magnetization sextupole is achieved for injection central inductions from 0.26 tesla on up. The effect of intrinsic magnetization is not fully corrected by the correctors at all fields going up or down, so additional superconductor was put into the correctors. The magnetization sextupole curve shown in Figure 17 is negative at low central inductions because of the fact that the intrinsic magnetization is over compensated for by the passive correctors. The area of the magnetization sextupole loop at low field shown in Figure 17 has been reduced, but perfect compensation has not been achieved. It is doubtful that much improvement can be actileved by changing the filament diameter; 12 microns is very close to the optimum corrector filament diameter. The decapole magnetization curve shown in Figure 17 is a little larger than the magnetization decapole loop shown in Figure 13.

The 20 micron filament passive correctors are shown in Figure 18. The correctors which are shown in Figure 18 can be made with round wires with a diameter of 1.078 millimeters and a copper to superconductor ratio of 1 . The correction of the magnetization sextupole and decapole is illustrated in Table 12 and Figure 19. (Figure 19 should be compared with Figure 5 in order to see the degree of magnetization correction.) Good correction of the magnetization sextupole is achieved for injection central inductions from 0.30 tesla on up. The effect of intrinsic magnetization is not fully corrected by the correctors at all fields going up or down, so additional superconductor was put into the correctors. The magnetization sextupole curve shown in Figure 19 is negative at low central inductions in part because the intrinsic magnetization is over compensated for by the passive correctors. The higher penetration field of the corrector filaments is responsible for the increased area of the magnetization sextupole loop in Figure 19. The decapole magnetization curve shown in Figure 19 is larger than the decapole loop shown in Figure 13.

The final case is the 27 micron filament case. The 27 micron filament passive correctors are shown in Figure 20. The correctors which are shown in Figure 18 can be made with round wires with a diameter of 0.808 millimeters and a copper to superconductor ratio of 0.9 (The corrector wire diameter is the same as the inner cable strand diameter.) The correction of the magnetization sextupole and decapole is illustrated in Table 13 and Figure 21. (Figure 21 should be compared with Figure 5.) Good correction of the magnetization sextupole is achieved for injection central inductions from 0.36 tesla on up. The effect of intrinsic magnetization is not fully corrected by the correctors at all fields going up or down, so additional superconductor was put into the correctors. The magnetization sextupole curve shown in Figure 21 is negative at low central inductions because of the fact that the intrinsic magnetization is over compensated for by the passive correctors. The higher penetration field of the corrector filaments is responsible for the increased loop area. The decapole magnetization loop shown in Figure 21 is larger than the loop shown in Figure 13. 
The attractive aspect of the 27 micron filament corrector is the size of the corrector strands. The radial space occupied by the currectors shown in Figure 20 is less than 1 millimeter including the ground plane insulation between the coil and the corrector. In addition, the corrector superconductor represents only 1.37 percent of the total superconductor in the magnet. Table 14 shows the effect of changing the turn around central induction on the magnetization sextupole correction at various injection inductions. When the turn around induction is 0.05 , good correction can be achieved from 0.36 tesla on up. When the turn around induction is increased to 0.25 tesla, good correction can be achieved at injection inductions from 0.47 tesla on up. With a turn around induction of 0.50 tesla, good correction starts at about 0.66 tesla. Figure 22 shows the sextupole and decapole magnetization curves for a turn arcund induction of 0.25 tesla. Unlike the 12 micron corrector case, one can not choose a variety of magnet cycles in order to achieve good compensation of flux creep decay.

It appears that the optimum passive superconductor filament diameter is about 12 microns. The optimum midplane angle for decapole compensation is about 3 degrees. Considerable variation can be allowed in both the angle and the filament diameter of the correctors in order to achieve good compensation. The location of the correctors in the magnet can be off by as much as 0.7 millimeters in a systematic way 21. Random variations of the passive corrector conductor positions can be as large as 1.5 to 2.0 millimeters. The important thing to stress is that the passive correctors are not windings. They are straight wires with a length equal to the magnetic length of tho dipole magnet. Experimental evidence at LBL suggests that the magnetic length of the magnetization multipoles is equal to the magnetic length of the dipole itself.

In general, good passive superconductor correction can be achieved for all values of the injection central induction above the penetration central induction for the magnet. (For the DX-201 SSC dipole, with a turn around induction of 0.05 tesla the magnet penetration central induction is just below 0.15 tesla. The magnet penetration induction is the magnetization sextupole turn around point with the field rising shown in Figure 4. When the turn around central induction is increased to 0.25 tesla, the DX-201 magnet penetration induction is 0.32 tesla. See Figure 5) If one wants to reduce the penetration central induction in comparison with the turn around point, on has to reduce the superconductor $J_{c}$ and or the filament diameter. Reducing the low field $J_{c}$ without reducing the high field $J_{c}$ does not appear to be possible in modern superconductors. The 12 micron corrector shows very good performance over a wide range of cential inductions and operating cycles. Improvement of the magnetization sextupole and decapole compensation may be possible if ferromagnetic correction is used to compensate out the sextupole and decapole due to the intrinsic magnetization of the superconductor. The technique of combining ferromagnetic correction and passive superconductor is investigated in the next section of this report. 
Figure 12

A QUARTER SECTION OF THE DX-201

SSC FIVE CENTIMETER BORE DIPOLE MAGNET

WITH 6 MICRON PASSIVE SUPERCONDUCTOR IN THE BORE

(Midplane Angle $=3$ degrees, $\mathrm{Cu}$ to $\mathrm{S} / \mathrm{C}$ Ratio $=1.3$ )

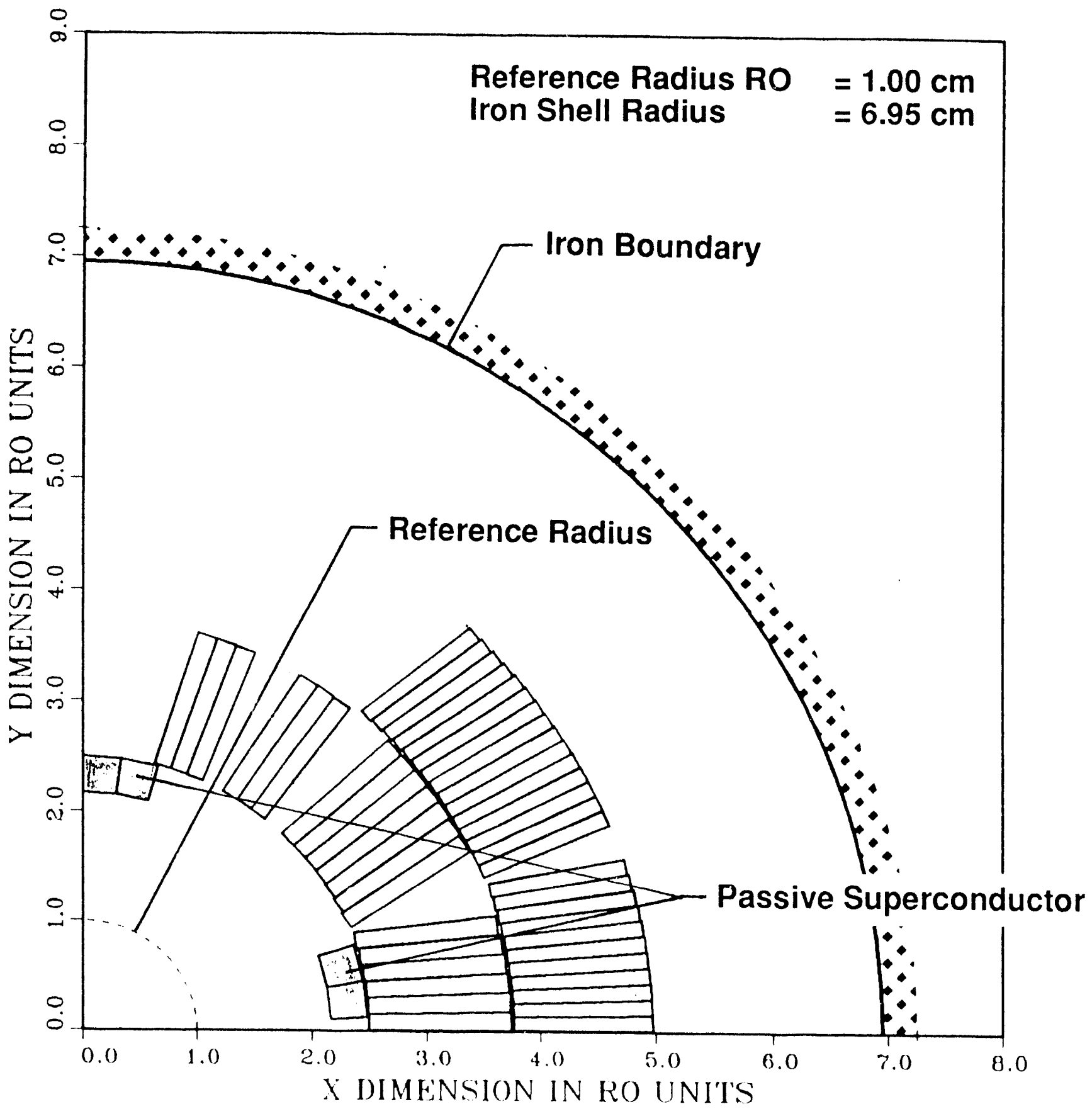


Table 9

\section{CORRECTION OF MAGNETIZATION SEXTUPOLE IN THE SSC DIPOLE BY INSTALLING PASSIVE SUPERCONDUCTING WIRES INSIDE THE DIPOLE COIL (6 micron filments, 3 degree midplane angle)}

\begin{tabular}{|c|c|c|c|c|}
\hline \multirow{3}{*}{$\begin{array}{l}\text { Central } \\
\text { Induction } \\
\text { (T) }\end{array}$} & \multicolumn{4}{|c|}{ Magnetization Multipole Ratios (units) } \\
\hline & \multicolumn{2}{|c|}{ Uncorrected Magnet } & \multicolumn{2}{|c|}{ Corrected Magnet } \\
\hline & $N=3$ & $\mathbf{N}=5$ & $\mathbf{N}=3$ & $N=5$ \\
\hline $\begin{array}{l}0.20 \\
0.25 \\
0.33 \\
0.40 \\
0.45 \\
0.50 \\
0.55 \\
0.60 \\
0.66 \\
0.70 \\
0.80 \\
0.90 \\
1.00 \\
\end{array}$ & $\begin{array}{l}-8.43 \\
-6.71 \\
-4.72 \\
-3.69 \\
-3.17 \\
-2.75 \\
-2.42 \\
-2.15 \\
-1.88 \\
-1.74 \\
-1.44 \\
-1.22 \\
-1.04\end{array}$ & $\begin{array}{l}0.68 \\
0.45 \\
0.25 \\
0.18 \\
0.15 \\
0.12 \\
0.10 \\
0.09 \\
0.08 \\
0.07 \\
0.06 \\
0.05 \\
0.04\end{array}$ & $\begin{array}{r}2.20 \\
0.87 \\
0.10 \\
0.03 \\
-0.04 \\
-0.08 \\
-0.07 \\
-0.06 \\
-0.04 \\
-0.04 \\
-0.03 \\
-0.03 \\
-0.03\end{array}$ & $\begin{array}{r}0.14 \\
0.06 \\
0.00 \\
-0.01 \\
-0.01 \\
-0.01 \\
-0.01 \\
-0.02 \\
-0.02 \\
-0.01 \\
-0.01 \\
-0.01 \\
-0.01\end{array}$ \\
\hline
\end{tabular}

The uncorrected magnet has 6 micron filament superconductor in all coil blocks. The corrected magnet has four strands of $3.232 \mathrm{~mm}$ diameter conductor symmetrically arranged about each magnet pole and four strands of $3.232 \mathrm{~mm}$ diameter conductor symmetrically arranged about the left and right magnet mid plane. The $3.232 \mathrm{~mm}$ strands have a copper to superconductor ratio of 1.3 to 1 and the filament diameter is 6 microns. The midplane angle of the corrector is 3 degrees. The corrector superconductor is 5.46 percent of the superconductor in the dipole coils.

The magnet central induction cycle goes from $6.6 \mathrm{~T}$ to $0.05 \mathrm{~T}$ to the central induction given in the table. 
Figure 13

MAGNETIZATION SEXTUPOLE AND DECAPOLE RATIOS AS A FUNCTION OF CENTRAL INDUCTIONS WITH A MINIMUM CYCLE INDUCTION OF 0.05 TESLA WITH 6 MICRON PASSIVE CORRECTORS

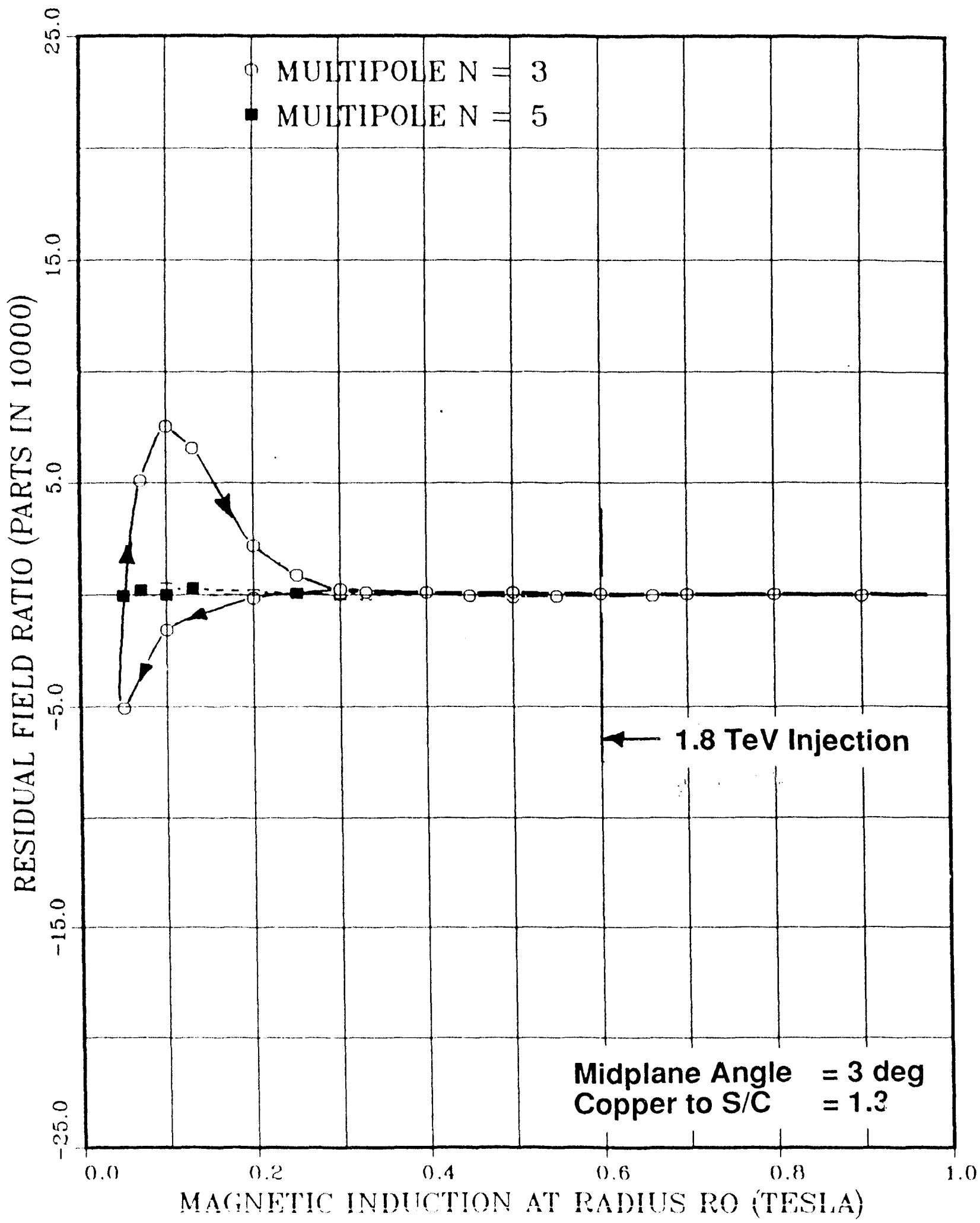


Figure 14

A QUARTER SECTION OF THE DX-201 SSC FIVE CENTIMETER BORE DIPOLE MAGNET

WITH 9.5 MICRON PASSIVE SUPERCONDUCTOR IN THE BORE (Midplane Angle $=3$ degrees, $\mathrm{Cu}$ to $\mathrm{S} / \mathrm{C}$ Ratio $=1.1$ )

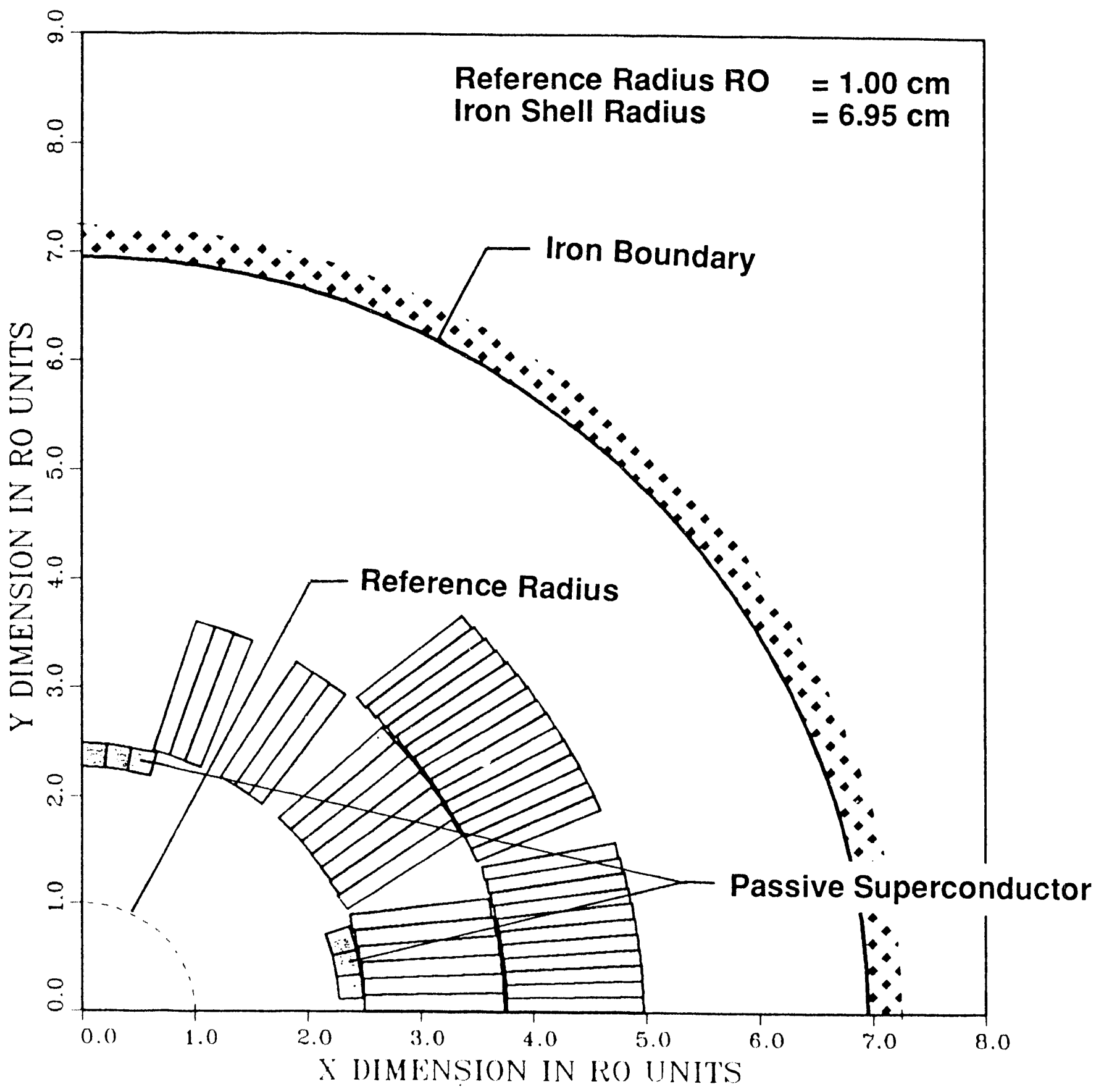


Table 10

CORRECTION OF MAGNETIZATION SEXTUPOLE IN THE SSC DIPOLE BY INSTALLING PASSIVE SUPERCONDUCTING WIRES INSIDE THE DIPOLE COIL (9.5 micron filments, 3 degree midplane angle)

\begin{tabular}{|c|c|c|c|c|}
\hline \multirow{3}{*}{$\begin{array}{l}\text { Central } \\
\text { Induction } \\
\text { (T) }\end{array}$} & \multicolumn{4}{|c|}{ Magnetization Multipole Ratios (units) } \\
\hline & \multicolumn{2}{|c|}{ Uncorrected Magnet } & \multicolumn{2}{|c|}{ Corrected Magnet } \\
\hline & $N=3$ & $N=5$ & $\mathbf{N}=\mathbf{3}$ & $N=5$ \\
\hline $\begin{array}{l}0.20 \\
0.25 \\
0.33 \\
0.40 \\
0.45 \\
0.50 \\
0.55 \\
0.60 \\
0.66 \\
0.70 \\
0.80 \\
0.90 \\
1.00\end{array}$ & $\begin{array}{l}-8.43 \\
-6.71 \\
-4.72 \\
-3.69 \\
-3.17 \\
-2.75 \\
-2.42 \\
-2.15 \\
-1.88 \\
-1.74 \\
-1.44 \\
-1.22 \\
-1.04\end{array}$ & $\begin{array}{l}0.68 \\
0.45 \\
0.25 \\
0.18 \\
0.15 \\
0.12 \\
0.10 \\
0.09 \\
0.08 \\
0.07 \\
0.06 \\
0.05 \\
0.04\end{array}$ & $\begin{array}{r}1.88 \\
1.22 \\
0.24 \\
0.12 \\
0.03 \\
-0.03 \\
-0.03 \\
-0.02 \\
-0.01 \\
-0.01 \\
-0.01 \\
-0.02 \\
-0.03\end{array}$ & $\begin{array}{r}0.19 \\
0.06 \\
0.01 \\
-0.01 \\
-0.01 \\
-0.01 \\
-0.01 \\
-0.01 \\
-0.01 \\
-0.01 \\
-0.01 \\
-0.01 \\
0.00\end{array}$ \\
\hline
\end{tabular}

The uncorrected magnet has 6 micron filament superconductor in all coil blocks. The corrected magnet has six strands of $2.155 \mathrm{~mm}$ diameter conductor symmetrically arranged about each magnet pole and six strands of $2.155 \mathrm{~mm}$ diameter conductor symmetrically arranged about the left and right magnet mid plane. The $2.155 \mathrm{~mm}$ strands have a copper to superconductor ratio of 1.1 to 1 and the filament diameter is 9.5 microns. The midplane angle of the corrector is 3 degrees. The corrector superconductor is 3.64 percent of the superconductor in the dipole coils.

The magnet central induction cycle goes from $6.6 \mathrm{~T}$ to $0.05 \mathrm{~T}$ to the central induction given in the table. 
Figure 15

MAGNETIZATION SEXTUPOLE AND DECAPOLE RATIOS AS A FUNCTION OF CENTRAL INDUCTIONS WITH A MINIMUM CYCLE INDUCTION OF 0.05 TESLA WITH 9.5 MICRON PASSIVE CORRECTORS

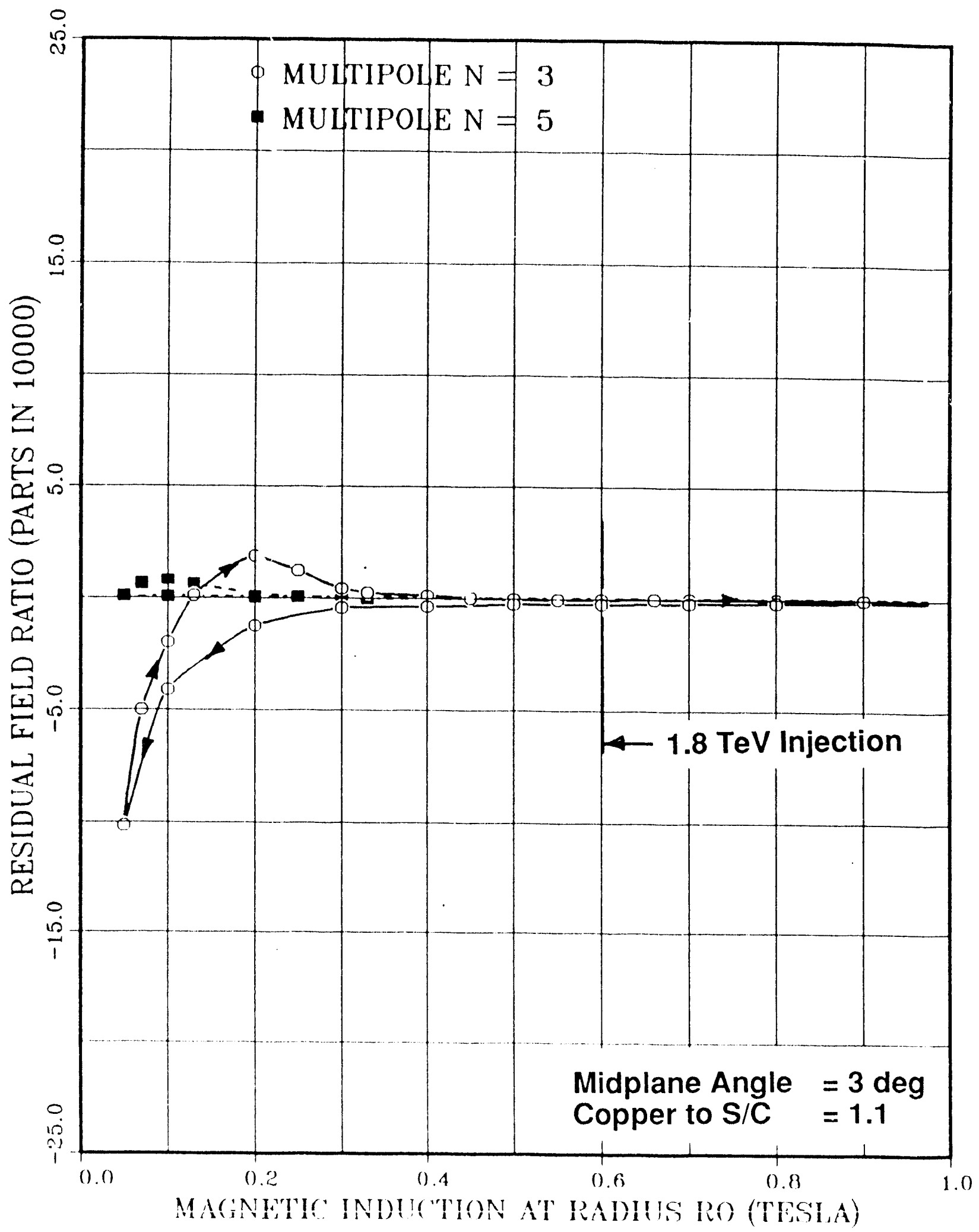


Figure 16

A QUARTER SECTION OF THE DX-201

SSC FIVE CENTIMETER BORE DIPOLE MAGNET

WITH 12 MICRON PASSIVE SUPERCONDUCTOR IN THE BORE

(Midplane Angle $=3$ degrees, $\mathrm{Cu}$ to $\mathrm{S} / \mathrm{C}$ Ratio $=0.9$ )

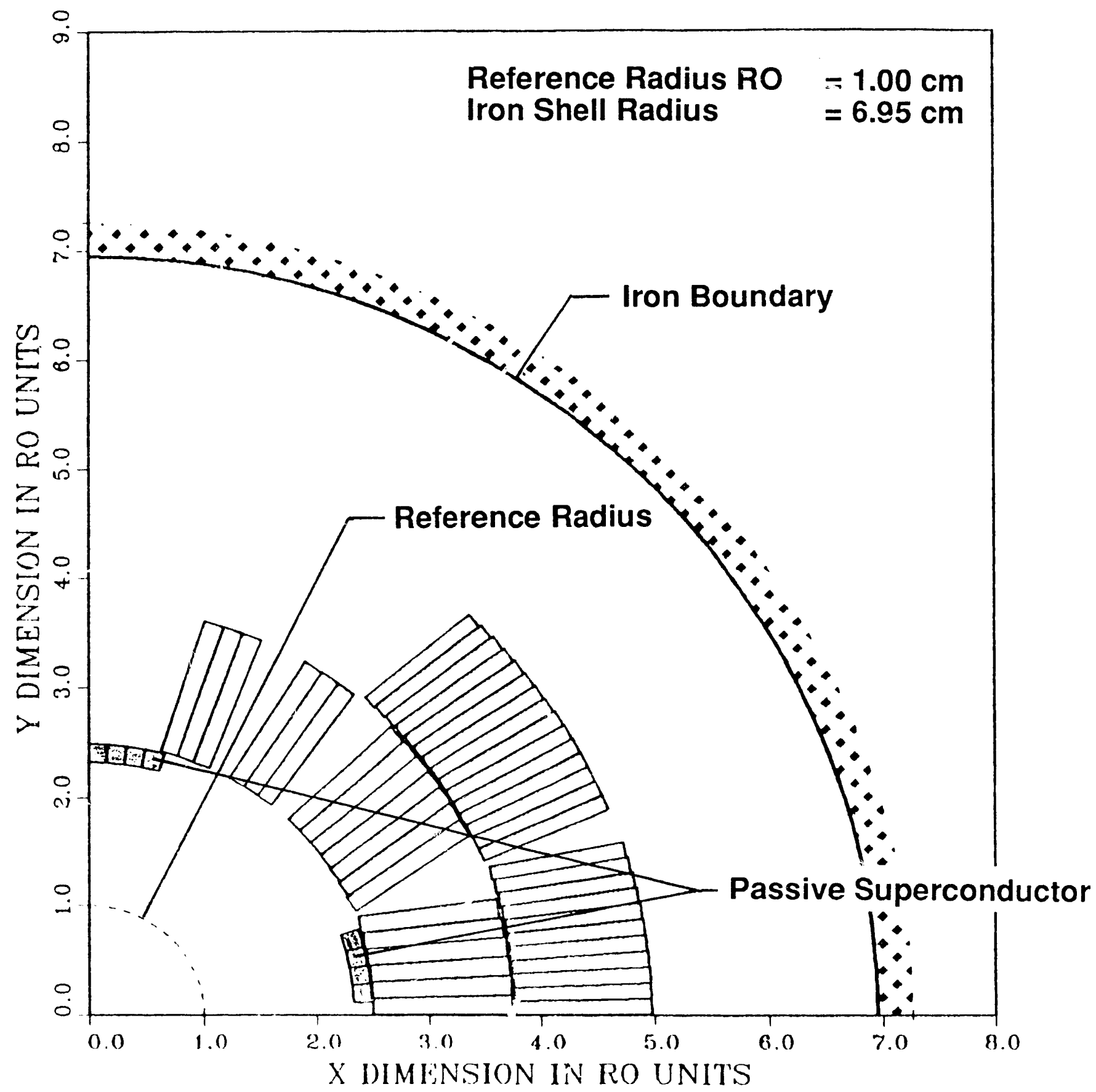


Table 11

CORRECTION OF MAGNETIZATION SEXTUPOLE IN THE SSC DIPOLE BY INSTALLING PASSIVE SUPERCONDUCTING WIRES INSIDE THE DIPOLE COIL (12 micron filments, 3 degree midplane angle)

\begin{tabular}{|c|c|c|c|c|}
\hline \multirow{3}{*}{$\begin{array}{l}\text { Central } \\
\text { Induction } \\
\text { (T) }\end{array}$} & \multicolumn{4}{|c|}{ Magnetization Multipole Ratios (units) } \\
\hline & \multicolumn{2}{|c|}{ Uncorrected Magnet } & \multicolumn{2}{|c|}{ Corrected Magnet } \\
\hline & $\mathbf{N}=\mathbf{3}$ & $N=5$ & $\mathbf{N}=3$ & $\mathbf{N}=\mathbf{5}$ \\
\hline $\begin{array}{l}0.20 \\
0.25 \\
0.33 \\
0.40 \\
0.45 \\
0.50 \\
0.55 \\
0.60 \\
0.66 \\
0.70 \\
0.80 \\
0.90 \\
1.00\end{array}$ & $\begin{array}{l}-8.43 \\
-6.71 \\
-4.72 \\
-3.69 \\
-3.17 \\
-2.75 \\
-2.42 \\
-2.15 \\
-1.88 \\
-1.74 \\
-1.44 \\
-1.22 \\
-1.04\end{array}$ & $\begin{array}{l}0.68 \\
0.45 \\
0.25 \\
0.18 \\
0.15 \\
0.12 \\
0.10 \\
0.09 \\
0.08 \\
0.07 \\
0.06 \\
0.05 \\
0.04\end{array}$ & $\begin{array}{r}0.34 \\
0.94 \\
0.21 \\
0.07 \\
-0.02 \\
-0.07 \\
-0.07 \\
-0.06 \\
-0.05 \\
-0.04 \\
-0.04 \\
-0.04 \\
-0.05\end{array}$ & $\begin{array}{r}0.27 \\
0.08 \\
0.01 \\
0.00 \\
0.00 \\
-0.01 \\
-0.01 \\
-0.01 \\
-0.01 \\
-0.01 \\
0.00 \\
0.00 \\
0.00\end{array}$ \\
\hline
\end{tabular}

The uncorrected magnet has 6 micron filament superconductor in all coil blocks. The corrected magnet has eight strands of $1.616 \mathrm{~mm}$ diameter conductor symmetrically arranged about each magnet pole and eight strands of $1.616 \mathrm{~mm}$ diameter conductor symmetrically arranged about the left and right magnet mid plane. The $1.616 \mathrm{~mm}$ strands have a copper to superconductor ratio of 0.9 to 1 and the filament diameter is 12 microns. The midplane angle of the corrector is 3 degrees. The corrector superconductor is 2.73 percent of the superconducter in the dipole coils.

The magnet central induction cycle goes from $6.6 \mathrm{~T}$ to $0.05 \mathrm{~T}$ to the central induction given in the table. 
Figure 17

MAGNETIZATION SEXTUPOLE AND DECAPOLE RATIOS AS A FUNCTION OF CENTRAI INDUCTIONS WITH A MINIMUM CYCLE INDUCTION OF 0.05 TESLA WITH 12 MICRON PASSIVE CORRECTORS

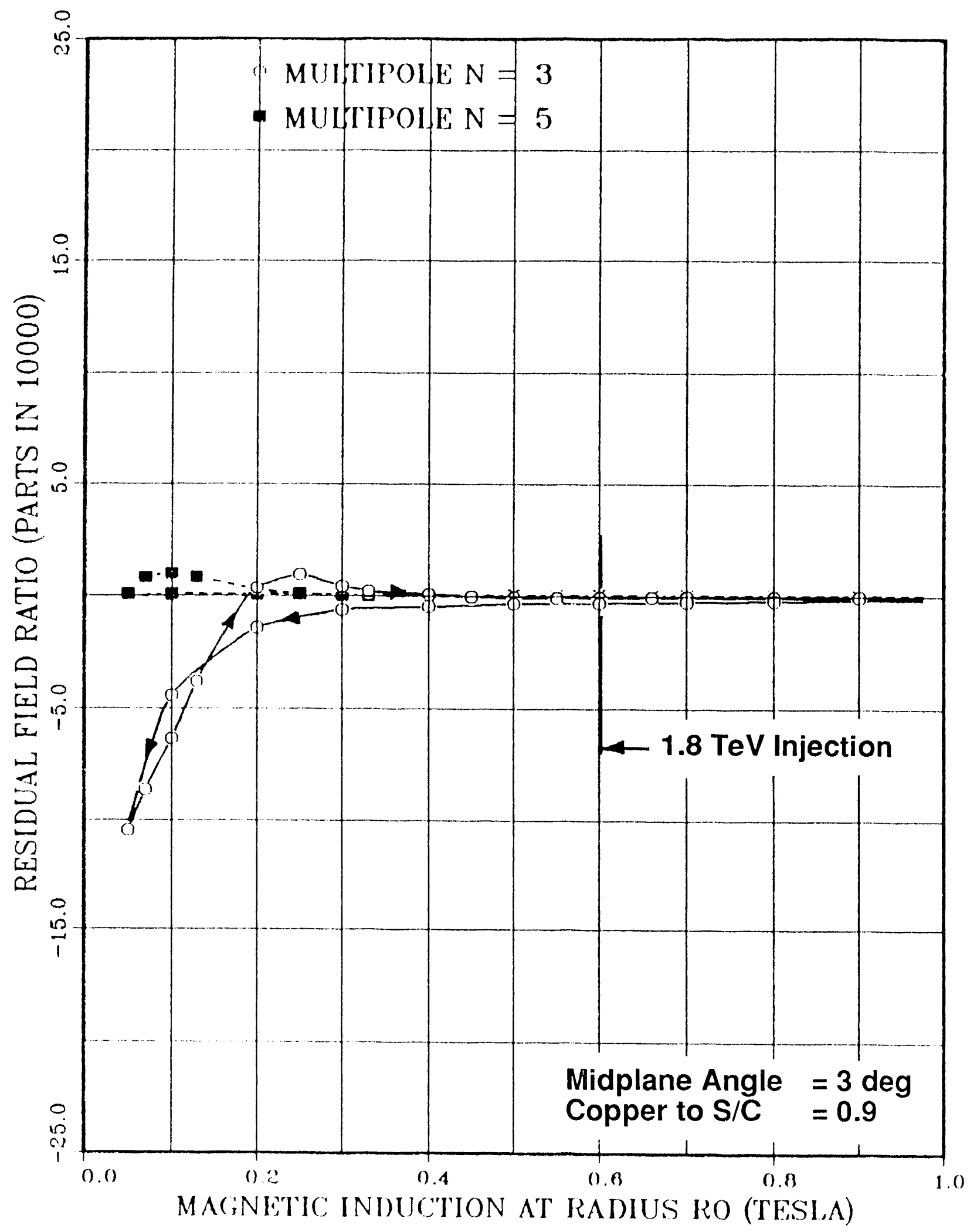


Figure 18

A QUARTER SECTION OF THE DX-201 SSC FIVE CENTIMETER BORE DIPOLE MAGNET

WITH 20 MICRON PASSIVE SUPERCONDUCTOR IN THE BORE

(Midplane Angle $=3$ degrees, $\mathrm{Cu}$ to $\mathrm{S} / \mathrm{C}$ Ratio $=1.0$ )

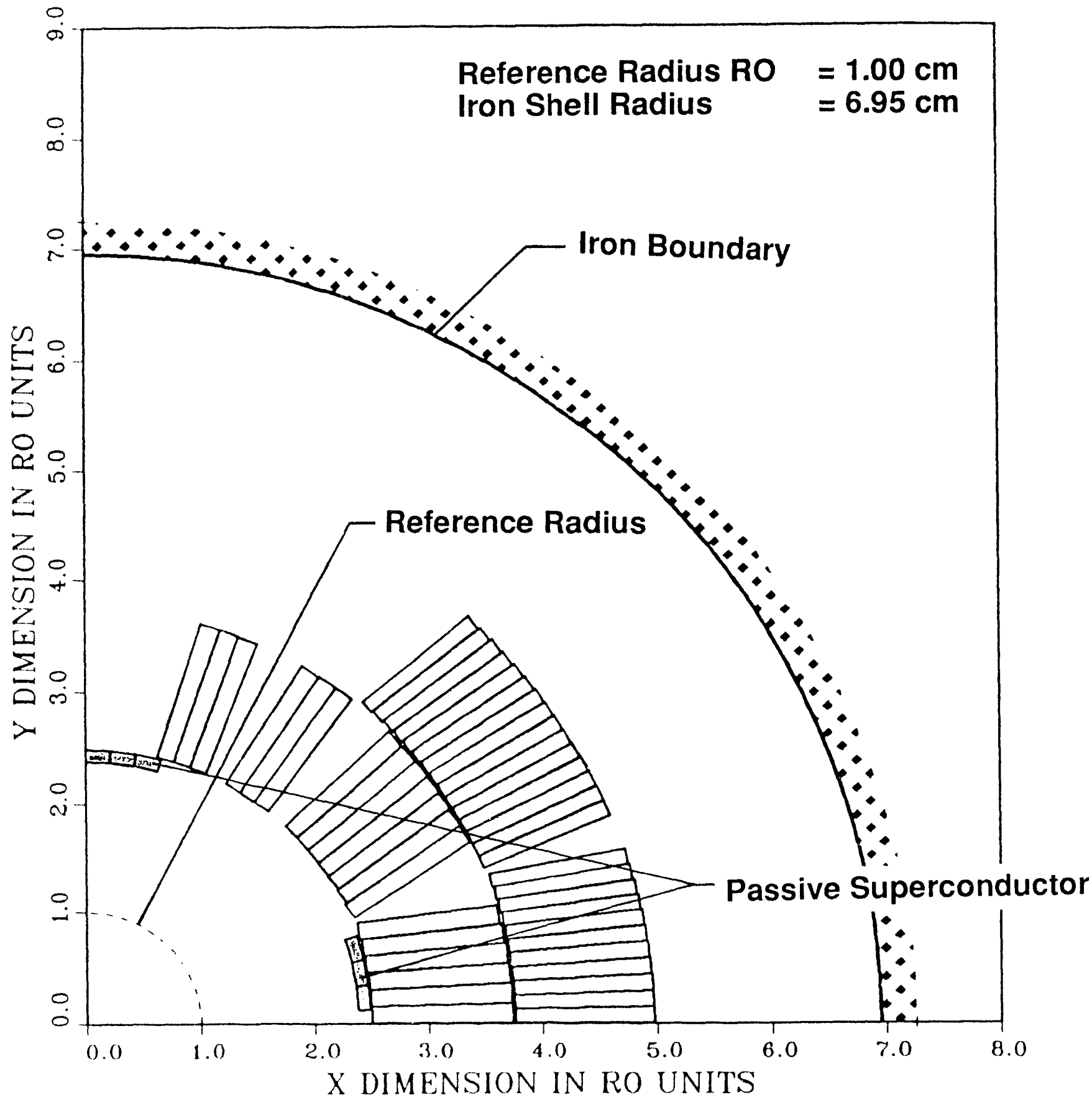


Table 12

CORRECTION OF MAGNETIZATION SEXTUPOLE IN THE SSC DIPOLE BY INSTALLING PASSIVE SUPERCONDUCTING WIRES INSIDE THE DIPOLE COIL (20 micron filments, 3 degree midplane angle)

\begin{tabular}{|c|c|c|c|c|}
\hline \multirow{3}{*}{$\begin{array}{l}\text { Central } \\
\text { Induction } \\
\text { (T) }\end{array}$} & \multicolumn{4}{|c|}{ Magnetization Multipole Ratios (units) } \\
\hline & \multicolumn{2}{|c|}{ Uncorrected Magnet } & \multicolumn{2}{|c|}{ Corrected Magnet } \\
\hline & $N=3$ & $N=5$ & $\mathbf{N}=3$ & $N=5$ \\
\hline $\begin{array}{l}0.20 \\
0.25 \\
0.33 \\
0.40 \\
0.45 \\
0.50 \\
0.55 \\
0.60 \\
0.66 \\
0.70 \\
0.80 \\
0.90 \\
1.00\end{array}$ & $\begin{array}{l}-8.43 \\
-6.71 \\
-4.72 \\
-3.69 \\
-3.17 \\
-2.75 \\
-2.42 \\
-2.15 \\
-1.88 \\
-1.74 \\
-1.44 \\
-1.22 \\
-1.04\end{array}$ & $\begin{array}{l}0.68 \\
0.45 \\
0.25 \\
0.18 \\
0.15 \\
0.12 \\
0.10 \\
0.09 \\
0.08 \\
0.07 \\
0.06 \\
0.05 \\
0.04\end{array}$ & $\begin{array}{r}-4.21 \\
-1.42 \\
-0.02 \\
0.06 \\
-0.03 \\
-0.08 \\
-0.10 \\
-0.09 \\
-0.07 \\
-0.07 \\
-0.06 \\
-0.06 \\
-0.07\end{array}$ & $\begin{array}{l}0.49 \\
0.20 \\
0.03 \\
0.00 \\
0.00 \\
0.00 \\
0.01 \\
0.01 \\
0.00 \\
0.00 \\
0.00 \\
0.00 \\
0.00\end{array}$ \\
\hline
\end{tabular}

The uncorrected magnet has 6 micron filament superconductor in all coil blocks. The corrected magnet has twelve strands of $1.078 \mathrm{~mm}$ diameter conductor symmetrically arranged about each magnet pole and twelve strands of $1.078 \mathrm{~mm}$ diameter conductor symmetrically arranged about the left and right magnet mid plane. The $1.078 \mathrm{~mm}$ strands have a copper to superconductor ratio of 1 to 1 and the filament diameter is $\mathbf{2 0}$ microns. The midplane angle of the corrector is 3 degrees. The corrector superconductor is 1.82 percent of the superconductor in the dipole coils.

The magnet central induction cycle goes from $6.6 \mathrm{~T}$ to $0.05 \mathrm{~T}$ to the central induction given in the table. 
Figure 19

MAGNETIZATION SEXTUPOLE AND DECAPOLE RATIOS AS A FUNCTION OF CENTRAL INDUCTIONS WITH A MINIMUM CYCLE INDUCTION OF 0.05 TESLA WITH 20 MICRON PASSIVE CORRECTORS

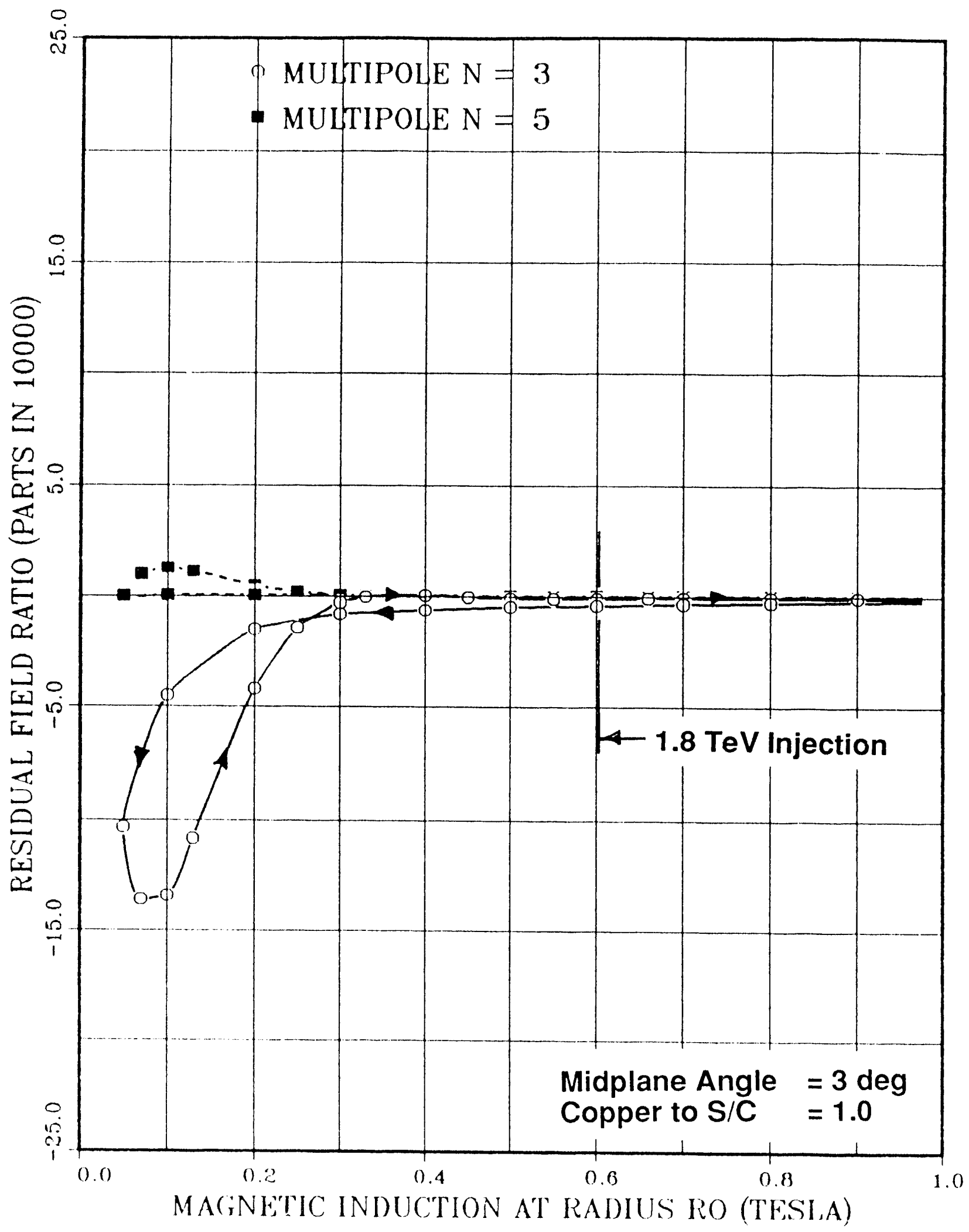


Figure 20

A QUARTER SECTION OF THE DX-201

SSC FIVE CENTIMETER BORE DIPOLE MAGNET

WITH 27 MICRON PASSIVE SUPERCONDUCTOR IN THE BORE

(Midplane Angle $=3$ degrees, $\mathrm{Cu}$ to $\mathrm{S} / \mathrm{C}$ Ratio $=0.9$ )

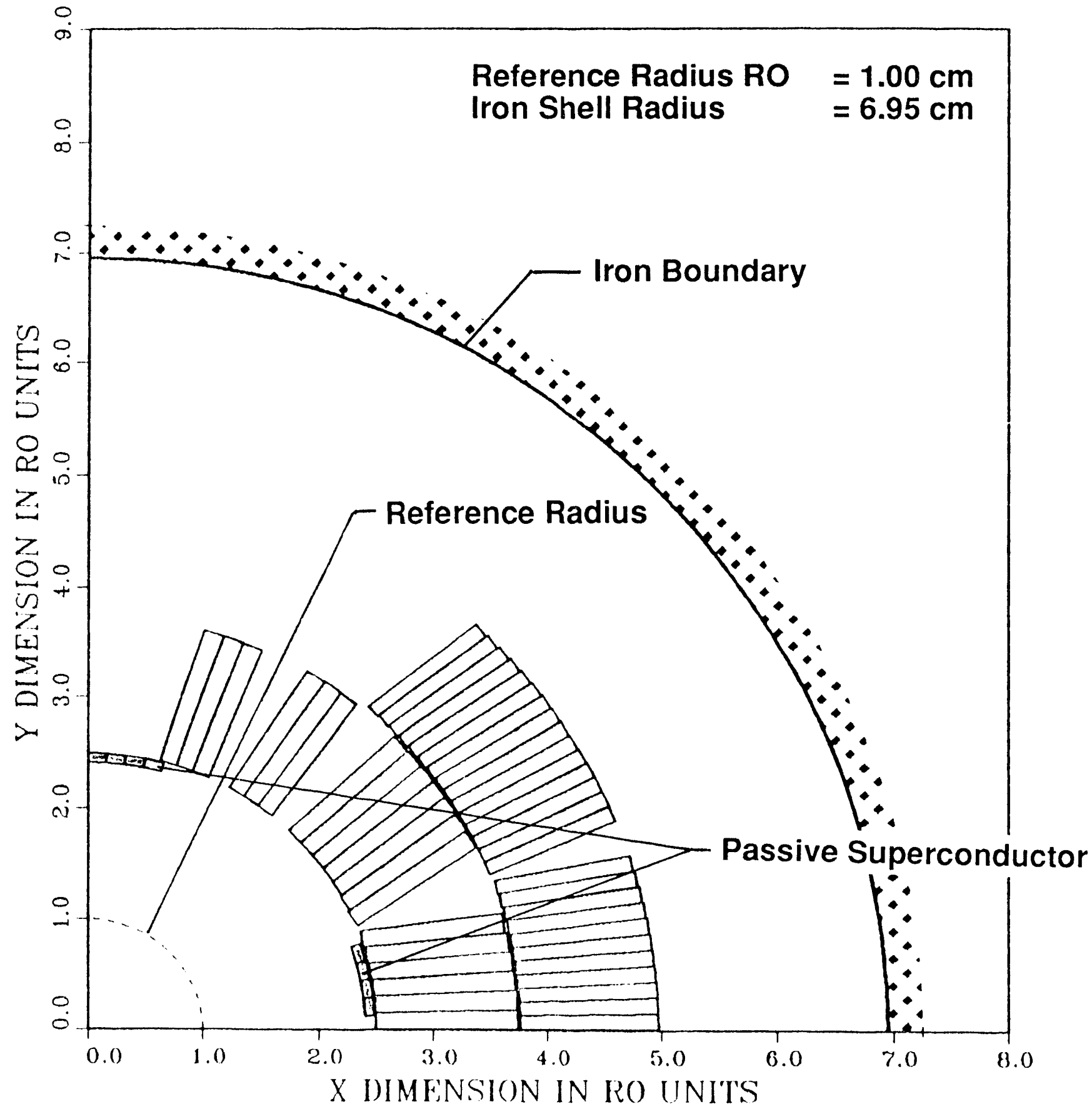


Table 13

CORRECTION OF MAGNETIZATION SEXTUPOLE IN THE SSC DIPOLE BY INSTALLING PASSIVE SUPERCONDUCTING WIRES INSIDE THE DIPOLE COIL (27 micron filments, 3 degree midplane angle)

\begin{tabular}{|c|c|c|c|c|}
\hline \multirow{3}{*}{$\begin{array}{l}\text { Central } \\
\text { Induction } \\
\text { (T) }\end{array}$} & \multicolumn{4}{|c|}{ Magnetization Multipole Ratios (units) } \\
\hline & \multicolumn{2}{|c|}{ Uncorrected Magnet } & \multicolumn{2}{|c|}{ Corrected Magnet } \\
\hline & $N=3$ & $N=5$ & $\mathbf{N}=\mathbf{3}$ & $N=5$ \\
\hline $\begin{array}{l}0.20 \\
0.25 \\
0.33 \\
0.40 \\
0.45 \\
0.50 \\
0.55 \\
0.60 \\
0.66 \\
0.70 \\
0.80 \\
0.90 \\
1.00 \\
\end{array}$ & $\begin{array}{l}-8.43 \\
-6.71 \\
-4.72 \\
-3.69 \\
-3.17 \\
-2.75 \\
-2.42 \\
-2.15 \\
-1.88 \\
-1.74 \\
-1.44 \\
-1.22 \\
-1.04 \\
\end{array}$ & $\begin{array}{l}0.68 \\
0.45 \\
0.25 \\
0.18 \\
0.15 \\
0.12 \\
0.10 \\
0.09 \\
0.08 \\
0.07 \\
0.06 \\
0.05 \\
0.04\end{array}$ & $\begin{array}{r}-6.79 \\
-3.29 \\
-0.72 \\
-0.02 \\
0.07 \\
0.03 \\
-0.01 \\
-0.02 \\
-0.01 \\
-0.01 \\
-0.01 \\
-0.02 \\
-0.03\end{array}$ & $\begin{array}{l}0.60 \\
0.29 \\
0.07 \\
0.01 \\
0.00 \\
-0.01 \\
-0.01 \\
-0.01 \\
-0.01 \\
-0.01 \\
0.00 \\
0.00 \\
0.00\end{array}$ \\
\hline
\end{tabular}

The uncorrected magnet has 6 micron filament superconductor in all coil blocks. The corrected magnet has sixteen strands of $0.808 \mathrm{~mm}$ diameter conductor symmetrically arranged about each magnet pole and sixteen strands of $0.808 \mathrm{~mm}$ diameter conductor symmetrically arranged about the left and right magnet mid plane. The $0.808 \mathrm{~mm}$ strands have a copper to superconductor ratio of 0.9 to 1 and the filament diameter is $\mathbf{2 7}$ microns. The midplane angle of the corrector is 3 degrees. The corrector superconductor is 1.37 percent of the superconductor in the dipole coils.

The magnet central induction cycle goes from $6.6 \mathrm{~T}$ to $0.05 \mathrm{~T}$ to the central induction given in the table. 
Figure 21

MAGNETIZATION SEXTUPOLE AND DECAPOLE RATIOS AS A FUNCTION OF CENTRAL INDUCTIONS WITH A MINIMUM CYCLE INDUCTION OF 0.05 TESLA WITH 27 MICRON PASSIVE CORRECTORS

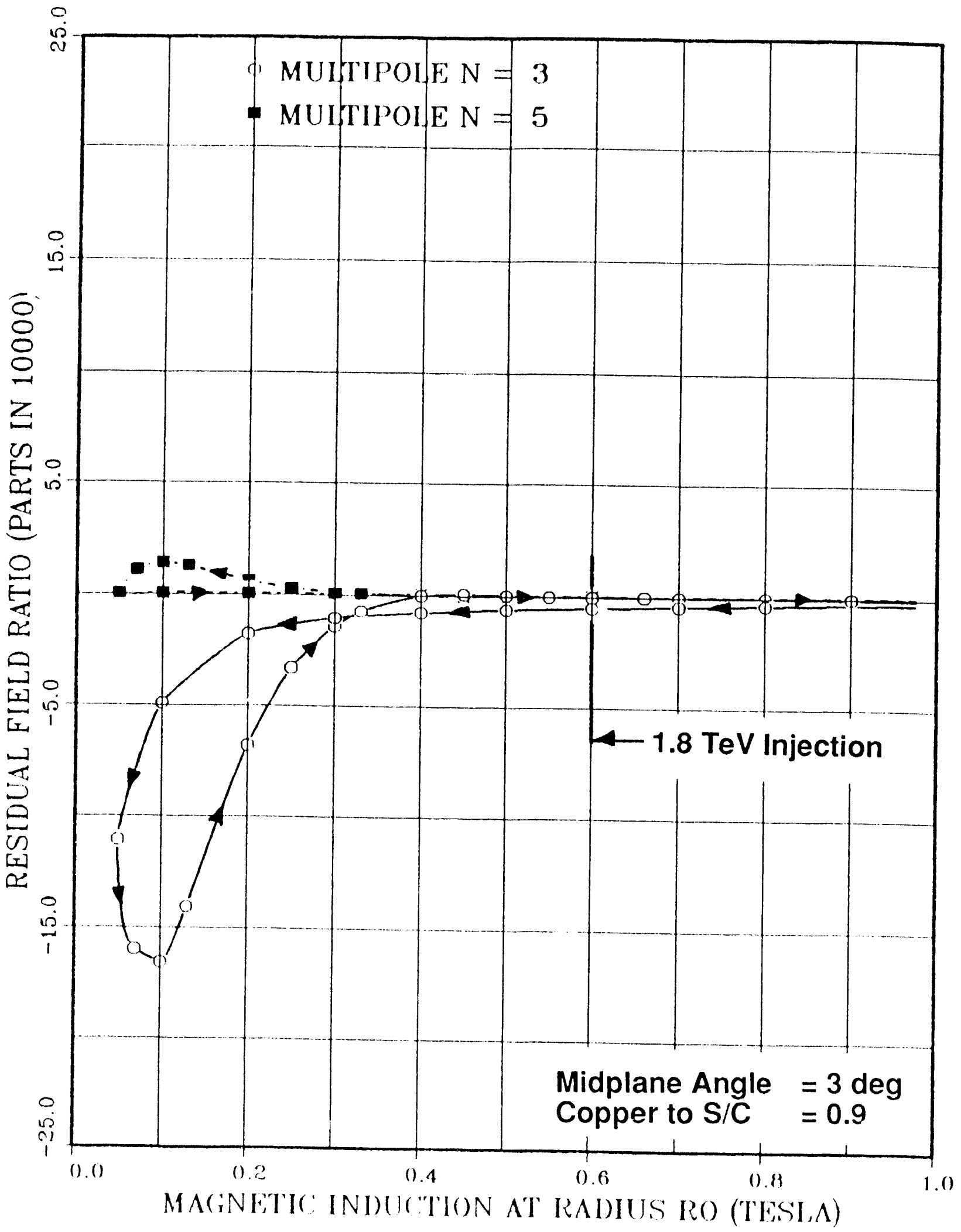


Table 14

THE EFFECT OF CHANGING THE TURN AROUND CENTRAL INDUCTION ON THE MAGNETIZATIONS SEXTUPOLE IN A SSC DIPOLE CORRECTED WITH PASSIVE SUPERCONDUCTING WIRES INSIDE THE COIL (27 micron filaments, 3 degree midplane angle)

\begin{tabular}{|c|c|c|c|}
\hline \multirow{2}{*}{$\begin{array}{l}\text { Central } \\
\text { Induction } \\
\text { (T) }\end{array}$} & \multicolumn{3}{|c|}{ Magnetization Sextupole Ratio (units) } \\
\hline & $\mathrm{Bo}=0.05 \mathrm{~T}$ & $\mathrm{Bo}=0.25 \mathrm{~T}$ & $B o=0.50 \mathrm{~T}$ \\
\hline $\begin{array}{l}0.25 \\
0.33 \\
0.40 \\
0.45 \\
0.50 \\
0.55 \\
0.60 \\
0.66 \\
0.70 \\
0.80 \\
0.90 \\
1.00\end{array}$ & $\begin{array}{r}-3.29 \\
-0.72 \\
-0.02 \\
0.07 \\
0.03 \\
-0.01 \\
-0.02 \\
-0.01 \\
-0.01 \\
-0.01 \\
-0.02 \\
-0.03\end{array}$ & $\begin{array}{r}-1.22 \\
-3.40 \\
-1.29 \\
-0.47 \\
-0.08 \\
0.04 \\
0.04 \\
0.02 \\
0.00 \\
-0.02 \\
-0.03 \\
-0.04\end{array}$ & $\begin{array}{r}-\cdot-\cdot- \\
-\cdots--.- \\
--.- \\
-0.60 \\
-1.69 \\
-0.94 \\
-0.25 \\
-0.04 \\
0.03 \\
-0.02 \\
-0.05\end{array}$ \\
\hline
\end{tabular}

The uncorrected magnet has 6 micron filament superconductor in all coil blocks. The corrected magnet has eight strands of $0.808 \mathrm{~mm}$ diameter conductor symmetrically arranged about each magnet pole and eight strands of $0.808 \mathrm{~mm}$ diameter conductor symmetrically arranged about the left and right magnet mid plane. The $0.808 \mathrm{~mm}$ strands have a copper to superconductor ratio of 0.9 to 1 and the filament diameter is 27 microns. The midplane angle of the corrector is 3 degrees. The corrector superconductor is 1.37 percent of the superconductor in the dipole coils.

The magnet central Induction cycle goes from 6.6 $\mathrm{T}$ to Bo to the central induction given in the table. 
Figure 22

MAGNETIZATION SEXTUPOLE AND DECAPOLE RATIOS AS A FUNCTION OF CENTRAL INDUCTIONS WITH A MINIMUM CYCLE INDUCTION OF 0.25 TESLA WITH 27 MICRON PASSIVE CORRECTORS

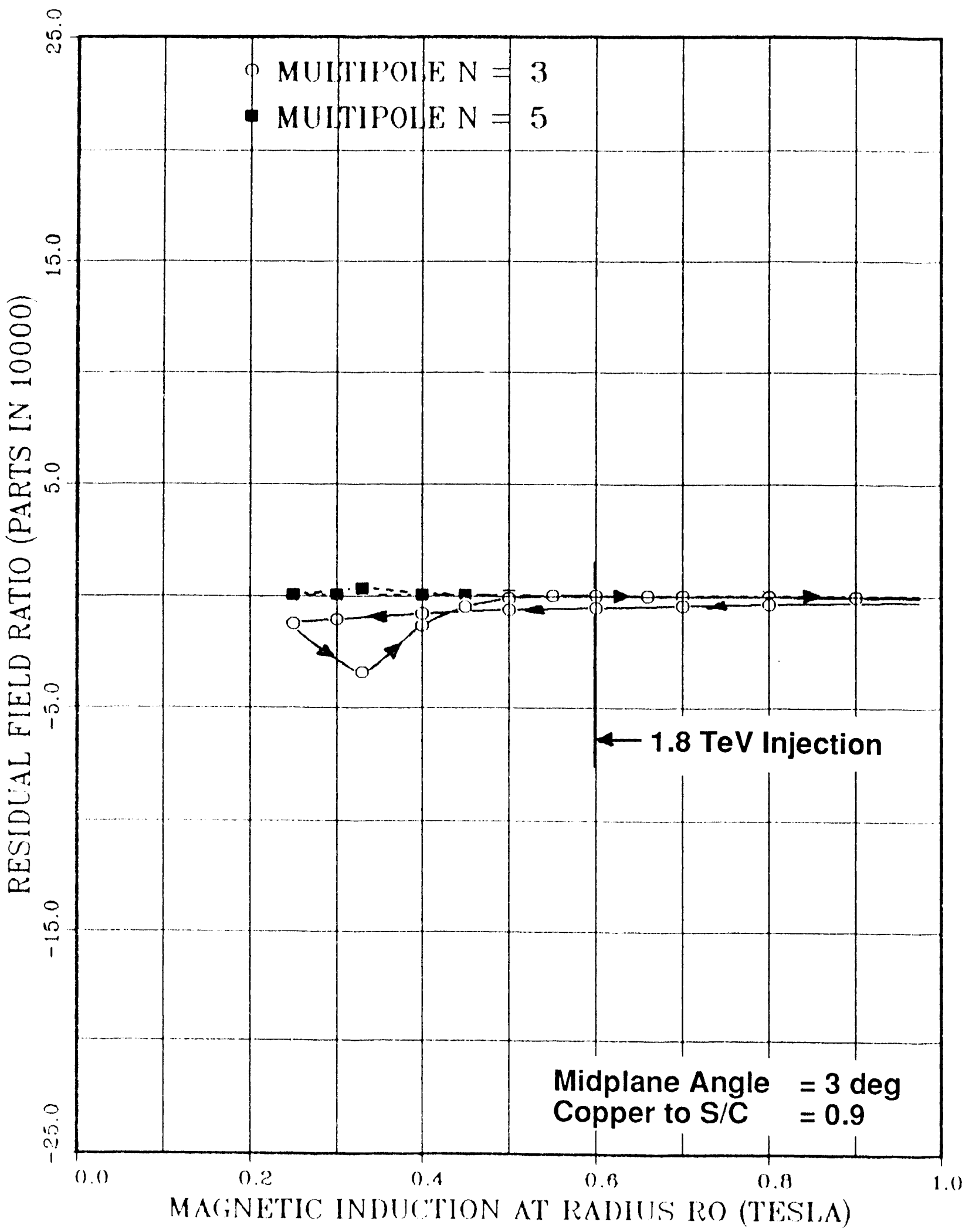




\section{CORRECTION WITH FERROMAGNETIC WIRES AND PASSIVE SUPERCONDUCTOR INSIDE THE MAGNET BORE}

Ferromagnetic correction of the magnetization sextupole has been suggested by Collings and others. In general two forms of ferromagnetic correction have be proposed:

1) The ferromagnetic material (nickel has been the material of choice) is put into or onto the superconducting strands 22,23 . Superconductor with a few nickel strands replacing niobium titanium strands has been fabricated and tested 24,25 . Nickel plated superconducting strand have also been fabricated and tested 25 . Calculations involving the use of these conductors in a SSC dipole suggest that this method of correction will work in principle 26.

2. Wires of ferromagnetic material (nickel, mu metal or iron) can be inserted into the inside of the magnet bore $\mathbf{1 3}$ or into one of the magnet wedges 27. In the NC-9 coil cross-section, the second wedge from the magnet midplane was attractive. In the DX-201 cross-section, the second wedge is close to the correct angle with respect to the midplane, so this method of correction is probably possible. Extra decapole may result.

The problem with ferromagnetic correction is the fact that the ferromagnetic detector does not compensate out the magnetization sextupole decay due to flux creep and related phenomena. Of lessor importance is the fact that ferromagnetic correction does not improve the temperature sensitivity of the magnetization sextupole.

Ferromagnetic correction may be used to correct out the magnetization sextupole due to the intrinsic magnetization of the superconductor. This form of magnetization is not subject to flux creep decay 28,29 and the temperature sensitivity of this form of magnetization is less than half that of the bulk current magnetization at $4.2 \mathrm{~K} 30$. As a result, flux creep decay compensation might not be changed and the temperature sensitivity may still be improved by a factor of four or five.

The DX-201 magnet quarter cross-section with 12 micron filament passive superconductor and a single small wire of nickel is shown in Figure 23. The 0.28 millimeter diameter nickel wire is located at a radius of 24.69 millimeters and at an angle of 46.5 degrees from the midplane. Since dipole symmetry applies, there are four such wires. The passive superconductor position is identical to the case shown in Figure 16. The copper to superconductor ration in the 1.616 millimeter diameter wires is 1.1 instead of 0.9 . The nickel is saturated when the central induction of the dipole reaches 0.32 tesla. The nickel compensates out the intrinsic magnetization sextupole at a central induction of 0.4 tesla. The nickel over compensates at central inductions above 0.4 tesla, and it under compensates at central inductions below 0.4 tesla. Ten percent less superconductor is need because the intrinsic magnetization of the coil superconductor is not compensated for by the passive superconductor corrector.

Table 15 compares the uncompensated magnet with the compensated magnet. Figure 24 shows that the shape of the magnetization sextupole curve is changed by the nickel wires on the bore. The region where good compensation of the magnctization sextupole is extended to central inducitions as low as 0.18 tesia (equivalent to an injection energy into the SSC of $0.54 \mathrm{TeV}$ ). 
Figure 23

A QUARTER SECTION OF THE DX-201

SSC FIVE CENTIMETER BORE DIPOLE MAGNET WITH 12 MICRON PASSIVE SUPERCONDUCTOR

AND NICKEL WIRE IN THE BORE

(Midplane Angle $=3$ degrees, $\mathrm{Cu}$ to $\mathrm{S} / \mathrm{C}$ Ratio $=1.0$

Nickel Wire Diameter $=0.28 \mathrm{~mm}$, Wire Angle $=\mathbf{4 6 . 5}$ degrees)

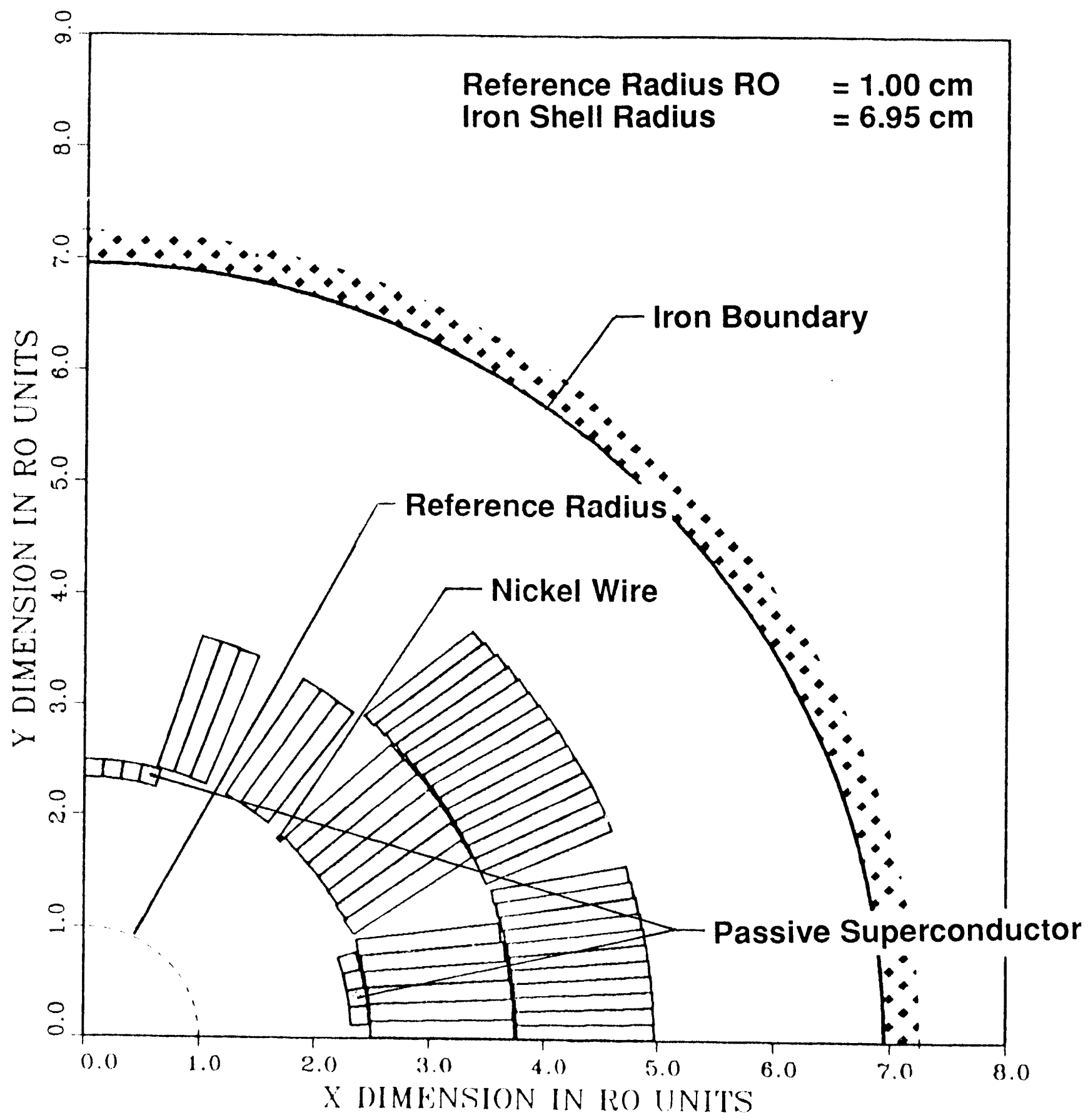


Table 15

\section{CORREOTION OF MAGNETIZATION SEXTUPOLE IN THE SSC DIPOLE BY INSTALLING PASSIVE SUPERCONDUCTING WIRES AND NICKEL WIRES ON THE INSIDE OF THE DIPOLE COIL}

\begin{tabular}{|c|c|c|c|c|}
\hline \multirow{3}{*}{$\begin{array}{l}\text { Central } \\
\text { Induction } \\
\text { (T) }\end{array}$} & \multicolumn{4}{|c|}{ Magnetization Multipole Ratios (units) } \\
\hline & \multicolumn{2}{|c|}{ Uncorrected Magnet } & \multicolumn{2}{|c|}{ Corrected Magnet } \\
\hline & $\mathbf{N}=3$ & $N=5$ & $N=3$ & $N=5$ \\
\hline $\begin{array}{l}0.20 \\
0.25 \\
0.33 \\
0.40 \\
0.45 \\
0.50 \\
0.55 \\
0.60 \\
0.66 \\
0.70 \\
0.80 \\
0.90 \\
1.00\end{array}$ & $\begin{array}{l}-8.43 \\
-6.71 \\
-4.72 \\
-3.69 \\
-3.17 \\
-2.75 \\
-2.42 \\
-2.15 \\
-1.88 \\
-1.74 \\
-1.44 \\
-1.22 \\
-1.04\end{array}$ & $\begin{array}{l}0.68 \\
0.45 \\
0.25 \\
0.18 \\
0.15 \\
0.12 \\
0.10 \\
0.09 \\
0.08 \\
0.07 \\
0.06 \\
0.05 \\
0.04\end{array}$ & $\begin{array}{l}-0.22 \\
0.47 \\
0.07 \\
-0.02 \\
-0.08 \\
-0.11 \\
-0.10 \\
-0.08 \\
-0.06 \\
-0.05 \\
-0.04 \\
-0.03 \\
-0.03\end{array}$ & $\begin{array}{r}0.29 \\
0.11 \\
0.02 \\
0.00 \\
0.00 \\
0.00 \\
-0.01 \\
-0.01 \\
-0.01 \\
-0.01 \\
0.00 \\
0.00 \\
0.00\end{array}$ \\
\hline
\end{tabular}

The uncorrected magnet has 6 micron filament superconductor in all coil blocks. The corrected magnet has eight strands of $1.616 \mathrm{~mm}$ diameter conductor symmetrically arranged about each magnet pole and eight strands of $1.616 \mathrm{~mm}$ diameter conductor symmetrically arranged about the left and right magnet mid plane. The $1.616 \mathrm{~mm}$ strands have a copper to superconductor ratio of 1.1 to 1 and the filamert diameter is 12 microns. The midplane angle of the corrector is 3 degrees. The nickel wire is located at an angle of 46.5 degrees and a radius of $24.69 \mathrm{~mm}$. The nickel wire diameter is $0.28 \mathrm{~mm}$.

The magnet central induction cycle goes from $6.6 \mathrm{~T}$ to $0.05 \mathrm{~T}$ to the central induction given in the table. 
Figure 24

MAGNETIZATION SEXTUPOLE AND DECAPOLE RATIOS AS A FUNCTION OF CENTRAL INDUCTION WITH A MINIMUM CYCLE INDUCTION OF 0.05 TESLA WITH 12 MICRON PASSIVE CORRECTORS AND NICKEL WIRE

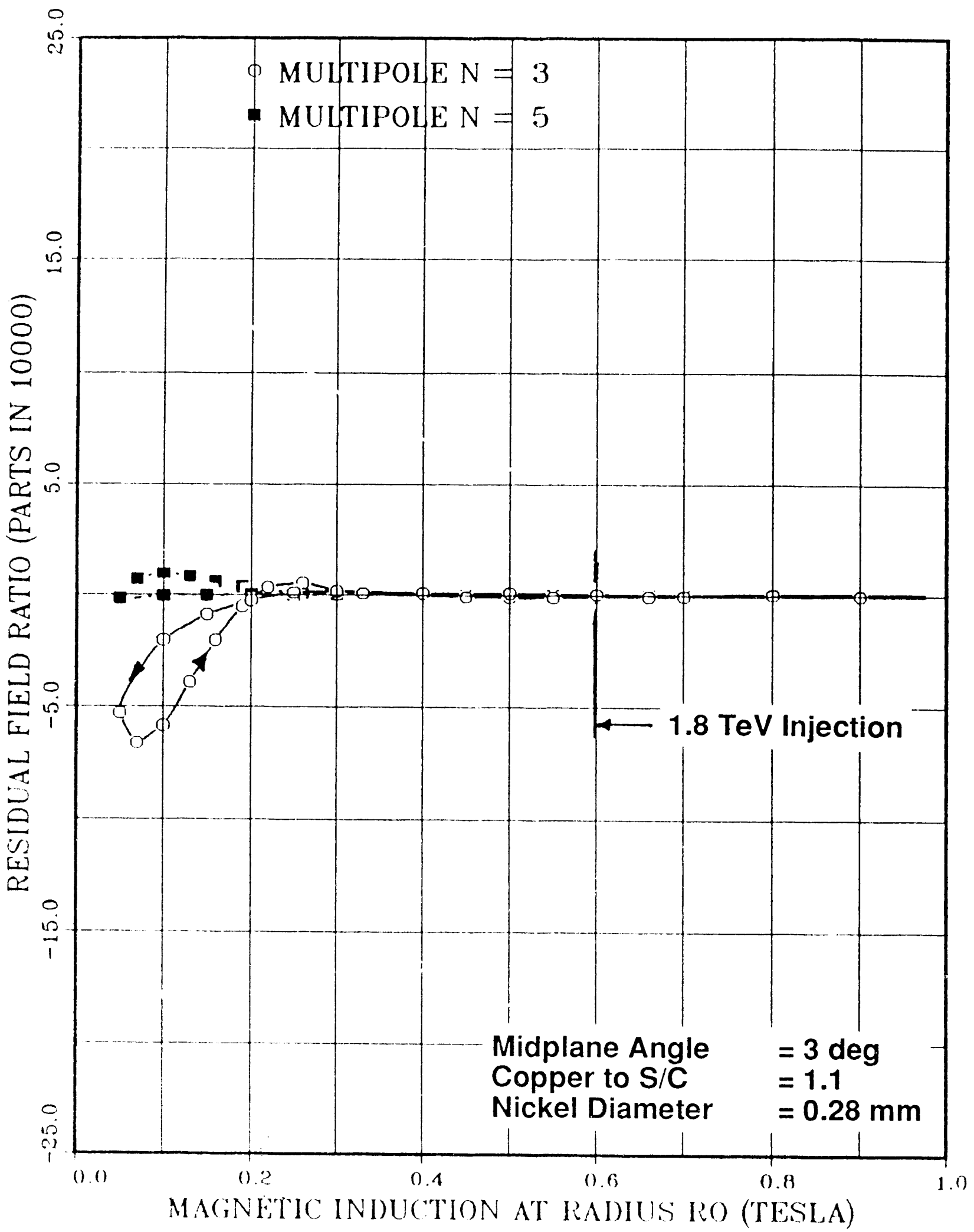




\section{COMPENSATION OF MAGNETIZATION SEXTUPOLE AND DECAPOLE DECAY DUE TO FLUX CREEP}

Experimental measurements at LBL of the decay of magnetization sextupole with and without passive correctors suggest that 60 to 70 percent of the magnetization sextupole decay can be eliminated using passive superconductor inside of the magnet bore ${ }^{19}$. The sign of the magnetization sextupole decay observed is dependent on the sign of the magnetization sextupole and where one is in the magnetization hysteresis loop. In general, when the magnetization sextupole is positive, the decay rate is negative and vice versa 31 . The behavior is not completely consistent in the flux reversal region of the the magnetization hysteresis loop. The dipoles have a complex field pattern and different parts of the dipole may be in different parts of the superconductor magnetization hysteresis loop. The magnetization sextupole decay observed in the LBL dipoles is probably not all due flux creep decay in the niobium titanium superconductor 19,32. More than one effect is probably responsible for the measured decay of the magnetization sextupole that LBL measured in its one meter long test dipoles.

It appears that the redistribution of the transport current in the cable as it is being held at field over a period of time contributes to the rate of magnetization sextupole decay observed in some dipole magnets. It has been observed in HERA dipoles $\mathbf{3 3}$ and 50 millimeter diameter 1.8 meter-long SSC dipoles $\mathbf{3 4}$ that the highest current and field the magnet sees has a definite effect on the rate of decay of the magnetization sextupole at injection. In both types of magnets, the magnetization sextupole decay rate is reduced about a factor of two when the highest current in the cycle is reduced from 6000 amperes to 3000 amperes. The changes in the decay rate are much smaller when the highest current is reduced below 3000 amperes. The mechanism for the reduction of the decay rate appears to be related to the cyclical changes in the magnetization dipole, sextupole and so on as one goes along the magnet bore. (In fact, all multipole skew and normal appear to show a cyclical behavior as on goes along the magnet bore. The mean value of the skew terms and the nonsymmetrical normal multipoles is very close to zero, but the amplitude of the oscillation may be ten units at a 10 millimeter radius as one goes along the magnet bore.) The period of the measured sextupole and other multipoles as one goes along the dipole axis is precisely the twist pitch of the cable in the magnet. (If the inner and outer layers have different twist pitches, a harmonic analysis would find both twist pitches with the inner cable twist pitch being dominant.) The difference between the decay rate when the magnet has been held a high current (6000 amperes) and at low currents (say 1500 amperes) appears to be proportional to the amplitude of the field variation as one moves along the dipole magnet.

Two things are clear from measurements, the magnetization sextupole decay is related to the highest and lowest currents the magnet sees and passive correction may remove some of the extra decay associated with the peak current the magnet has seen. The decay observed in the D-16B dipole with correction is a factor of two lower for the 3000 ampere cycle as compared to the 6000 ampere cycle 19 . Without correction, there is also about a factor of two difference in the decay rates observed in dipole magnets. Changing the peak current from 6000 amperes to 3000 amperes appears to increase the percentage of the decay that is compensated by the passive corrector. 
Experiments with the high critical temperature superconductor $\mathrm{YBCO}$ at liquid nitrogen temperature $(77 \mathrm{~K})$ show that it has a very high flux creep decay rate. The experiment by Kwasnitza and Widmer $\mathbf{3 5}$ shows that flux creep decay in YBCO can be eliminated entirely in the flux penetration region region of the superconductor hysteresis loop. Results from the Kwasnitza and Widmer experiment are shown in Figure 25. Some experiments by A. ghosh of the Brookhaven National Laboratory 36 suggest that this might be true for niobium titanium as well. This may be the explanation for the reduced flux creep decay observed at LBL when there was overshoot in the power supply just before the decay was measured 37 . This suggests that altering the magnet cycle so that most of the dipole superconductor is in the penetration region of the hysteresis loop will greatly reduce the flux creep decay. Passive correction must be applied in order to avoid the sudden jump in the magnet sextupole as one starts to accelerate the beam.

Holding the current at some level such as 1000 amperes as one decreases the current may reduce the non-flux creep magnetization decay in the magnet at injection 38. It appears that a combination of the passive superconductor inside the magnet bore and an altered machine cycle will reduce the magnetization sextupole and the decay of that sextupole to an acceptable level for injection into the SSC. This requires some experimental in order to establish the proper operating cycle for the machine. The magnet to magnet variation of the decay of the magnetization sextupole may still be of some concern.

\section{CONCLUDING COMMENTS}

All of the passive superconductor methods of magnetization sextupole correction will reduce the magnetization sextupole by an order of magnitude in the 50 millimeter bore DX-201 SSC dipole from injection central inductions of 0.36 tesla on up. (This type of correction would permit injection into the SSC main ring at injection energies from 1.1 TeV on up.) Magnetization sextupole is reduced when the field is falling as well as rising. Magnetization decapole reduction can be achieved with some types of correction but not with others. The separate corrector inside the magnet bcre permit one to correct the sextupole and decapole over a wide range of magnet cycles if the right filament diameter is chosen. Increasing the filament diameter in block 1 of the dipole decreases magnetization sextupole and dipole but it increases the magnetization decapole.

All of the passive superconductor methods of correction will greatly decrease the sensitivity of the injection field quality to changes in the magnet operating temperature. The decay of the magnetization sextupole will be reduced by the passive correctors alone. A combination of passive superconductor correction with an altering of the magnet charge and discharge cycle should reduce the magnetization sextupole decay to acceptable levels. More experimental work is need to determine the magnet cycle which is optimum for reducing the decay of the magnetization sextupole. 


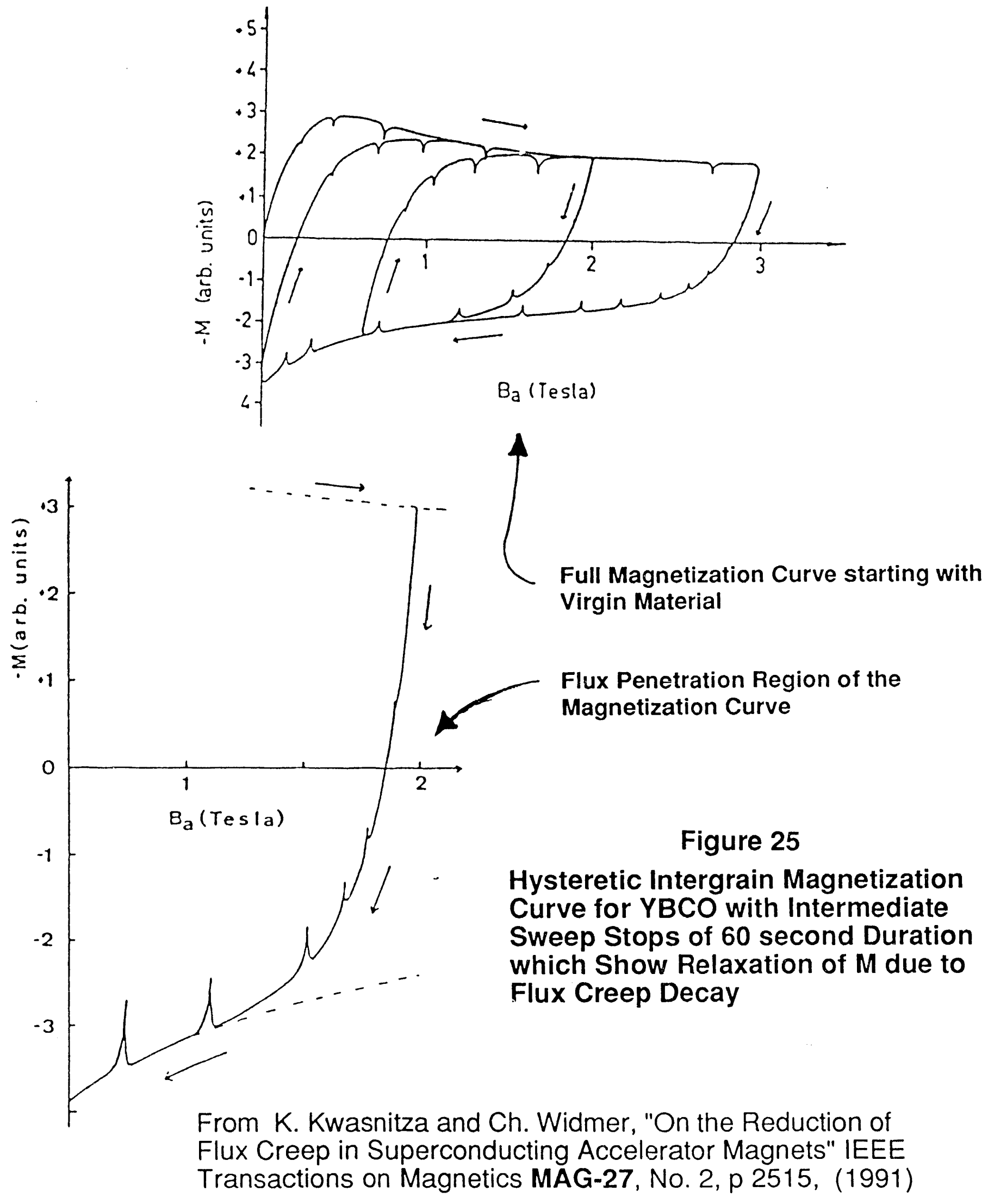




\section{ACKNOWLEDGEMENTS}

The author acknowledges conversations he has had with Rae Steining and Jack Peterson of the SSC Laboratory concerning magnetization sextupole, and the decay of that sextupole. The author also acknowledges conversations he has had with $\mathrm{A}$. K Ghosh of the Brookhaven National Laboratory concerning various superconductor magnetization issues.

The work that went into this report was supported by the Office of High Energy and Nuclear Physics, High Energy Physics Division, United State Department of Energy, under contract number DE-AC03-76SF00098

\section{REFERENCES}

1. M. A. Green, "Magnetic Measurements of a Superconducting Dipole Magnet", Lawrence Radiation Laboratory Report UCID-3494, Dec. 1970

2. M. A. Green, IEEE transactions on Nuclear Science, NS-18, No. 3, p 664, (1971)

3. M. A. Green, "Magnetic Measurements and Other Tests of the Los Alamos 6-inch Quadrupole Doublet", Lawrence Radiation Laboratory Report UCID-3491, Nov. 1970

4. M. A. Green, "The Theory of Residual Field in Two Dimensional Dipoles and Quadrupoles without Iron Shields", Lawrence Radiation Laboratory Report UCID-3508, March 1971

5. M. A. Green, "Residual Fields in Superconducting Magnets", Proceedings of the MT-4 Conference, Brookhaven National Laboratory, p 339, (1972)

6. R. B. Palmer et. al., "The Two Layer Isabelle Cable Magnet Description and Results", Brookhaven National Laboratory Isabelle Project Technical Note 320, Sept. 1981

7. B. C. Brown et. al., IEEE Transactions on Magnetics, MAG-21, No. 2, p 979, (1985)

8. M. A. Green, "Fields Generated within SSC Magnets Due to Persistent Currents in the Superconductor", Proceedings of the Ann Arbor Workshop on SSC Issues, Dec. 1983

9. R. Steining, private communication concerning issues which affect the SSC dipole magnet bore diameter and the SSC injection energy.

10. K. Balewski, et. al., IEEE Transactions on Magnetics, MAG-23, No. 2, p 1233, (1987)

11. W. Gilbert et. al., IEEE Transactions on Magnetics, M4G-21, No. 2, p 486 , (1985) 
12. B. C. Brown and H. E. Fisk, "The Idea of Passive Superconductor correction", presented at the Snowmass SSC Workshop, 1984

13. M. A. Green, IEEE Transactions on Magnetics, MAG-23, No. 2, p 506, (1987)

14. M. A. Green, "The SCMAG Series of Programs for Calculating Superconducting Dipole and Quadrupole Magnets", Proceedings of the CUBE Symposium, Lawrence Livermore Laboratory, Oct. 23-25, 1974

15. M. A. Green, "Magnetic Field Program, Instructions for the Use of SCMAG01, SCMAG02, SCMAG03, and SCMAG04", Lawrence Berkeley Laboratory Engineering Note M5692, LBID-342, Feb. 1981

16. B. C. Brown, private communication concerning the use of various size superconductor filaments in a dipole to control the magnetization sextupole during at low fields.

17. H. E. Fisk et. al., "Report on the Fermilab Passive Superconductor Test", ICFA Workshop, 1986

18. M. A. Green et. al. "Correction of the Magnetization Sextupole in One Meter Long Dipole Magnets Using Passive Superconductor", Supercollider 2, p 389, Plenum Press, New York, 1990

19. M. A. Green et. al., IEEE Transactions on Magnetics, MAG-27, No. 2, p 1989 (1991)

20. A. K. Ghosh et. al., IEEE Transactions on Magnetics, MAG-23, No. 2, p 1724, (1987)

21. M. A. Green, "Passive Superconductor a Viable Method of Controlling Magnetization Multipoles in the SSC Dipole", Supercollider 1, p 351, Plenum Press, New York, 1989

22. E. W Collings, et. al., Advances in Cryogenic Engineering 36, p 247, Plenum Press, New York, (1990)

23. M. A. Green, "Control of Higher Multipoles in SSC Dipole Magnets Due to Superconductor Magnetization Using Ferromagnetic Material in the Superconductor Matrix", Lawrence Berkeley Laboratory report LBID-1532, Sept. 1989

24. G. Iwaki, et. al., "Current Developments of the Cu/Nb-Ti Superconducting Cables for SSC in Hitachi Cable Ltd.", Supercollider 2, Plenum Press, New York, (1990)

25. E. W. Collings, et. al., IEEE Transactions on Magnetics, MAG-27, No. 2, p 1787, (1991) 
26. M. A. Green, et. al., "Ferromagnetic Material in the Superconductor and Its Effect on the Magnetization Sextupole and Decapole in the SSC Dipoles at Injection", to be published in Supercollider 3, Plenum Press, New York, (1991), LBL-30403

27. M. A. Green, "Control of Higher Multipoles in SSC Dipole Magnets Due to Superconductor Magnetization Using Ferromagnetic Material in the Dipole Wedge", Lawrence Berkeley Laboratory report LBID-1533, Sept. 1989

28. P. W. Anderson, "Theory of Flux Creep in Hard Superconductors", Physical Review Letters 9, p 309, (1962)

29. M. B. Beasley, et. al. "Flux Creep in Type II Superconductors", Physical Review, 181, p 682, May 1969

30. M. A. Green, "Generation of the Jc, Hc, Tc, Surface for Commercial Superconductor Using Reduced State Parameters", Lawrence Berkeley Laboratory Report LBL-24875 UC-406, April 1988

31. W. S. Gilbert, private communication concerning unpublished data on flux creep decay in one meter dipole magnets taken at various points in the magnet current cycle.

32. R. Steining, "A Possible Mechanism for Enhanced Persistent Current Sextupole Decay in SSC Dipoles". Superconducting Super Collider Laboratory Report SSCL-359, January 1991

33. H. Brueck, et. al., "Observation of a Periodic Pattern in the Persistent Current Fields of the Superconducting HERA Dipole Magnets" DESY-HERA Report 91-01, January 1991

34. M. Wake, et. al., "Tests of 1.5 Meter 50 Millimeter SSC Collider Dipoles at Formilab", to be published in the Proceedings of the IEEE Particle Accelerator Conference, San Francisco, CA, May 6-9, 1991

35. K. Kwasnitza and C. Widmer, IEEE Transactions on Magnetics, MAG-27, No 2, p 2515, (1991)

36. A. K. Ghosh, et. al., Advances in Cryogenic Engineering 36, p 27, Plenum Press, New York, (1990)

37. W. S. Gilbert, et. al., Advances in Cryogenic Engineering 36, p 223, Plenum Press, New York, (1990)

38. P. Schmueser, private communication concerning the effect of the magnet field cycle on the flux creep decay in HERA dipoles. 

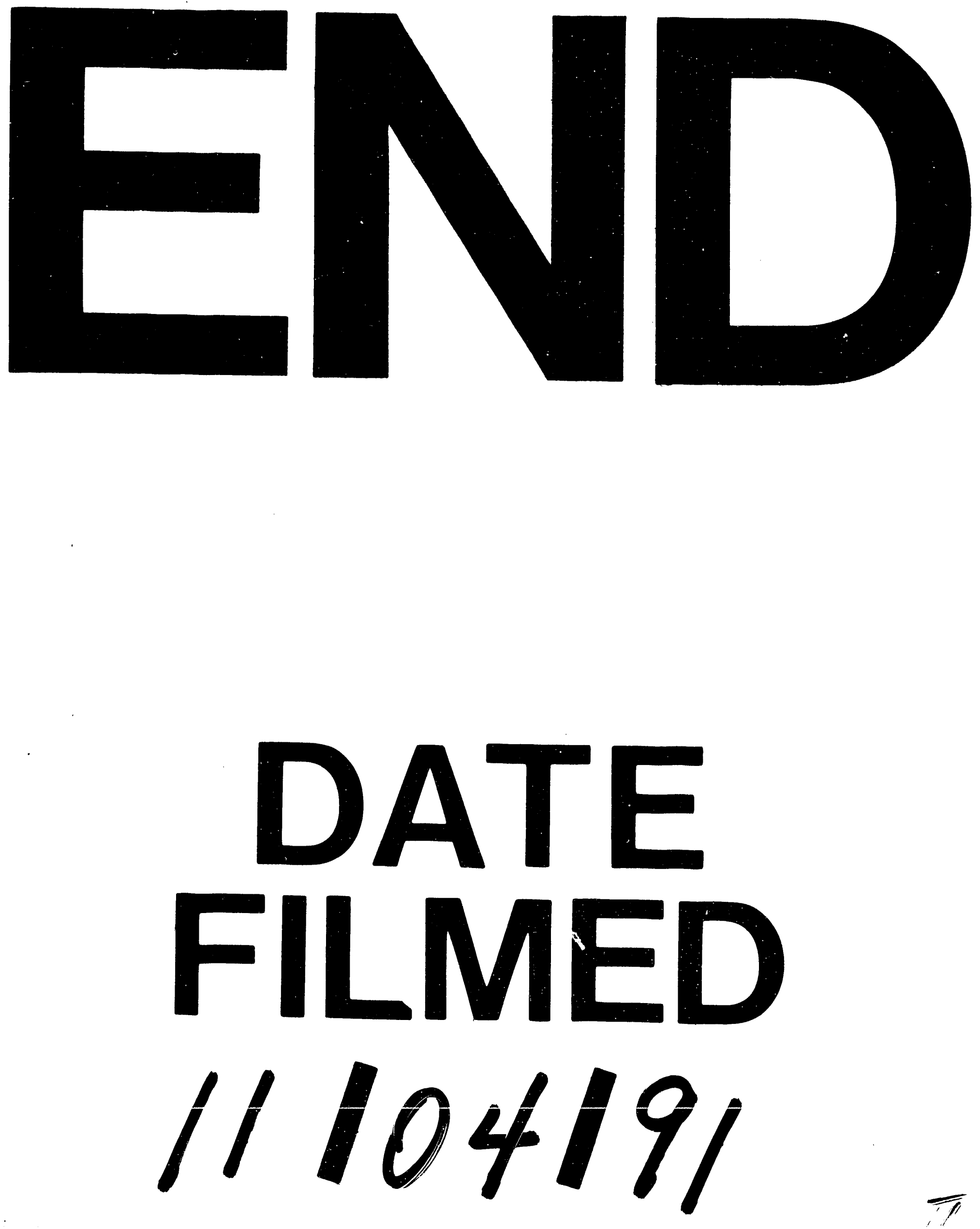

$\overline{1} 1$ 
